(ㄷ Г.Р. Галстян ${ }^{1 *}$, Е.Г. Старостина², Н.Н. Яхно ${ }^{3}$, И.В. Гурьева ${ }^{4}$, М.В. Чурюканов ${ }^{3}$, И.А. Строков ${ }^{3}$, А.Ю. Токмакова ${ }^{1}$, М.Л. Кукушкин ${ }^{5}$, А.И. Мартынов ${ }^{6}$, М.В. Шестакова'

${ }^{1}$ Национальный медицинский исследовательский центр эндокринологии, Москва

${ }^{2}$ Московский областной научно-исследовательский клинический институт им. М.Ф. Владимирского, Москва

${ }^{3}$ Первый Московский государственный медицинский университет им. И.М. Сеченова (Сеченовский университет), Москва

${ }^{4}$ Российская медицинская академия непрерывного профессионального образования, Москва

${ }^{5} \mathrm{HИИ} \mathrm{общей} \mathrm{патологии} \mathrm{и} \mathrm{патофизиологии} \mathrm{РАН,} \mathrm{Москва}$

${ }^{6}$ Московский Государственный медико-стоматологический университет им. А.И. Евдокимова, Москва

Диабетическая периферическая нейропатия (ДПН) - распространенное хроническое осложнение сахарного диабета (СД), значительно нарушающее самочувствие, качество жизни и функционирование пациентов. Показатели распространенности ДПН в РФ колеблются от 0,1\% до 67,2\% при СД 1 типа и от 0,1 до 42,4\% при СД 2 типа. Однако, судя по широкомасштабным эпидемиологическим исследованиям, истинная распространенность ДПН гораздо выше (50-70\%), причем ее болевая форма встречается у 16-30\% пациентов. Несмотря на то что периферическая нейропатия остается самым распространенным хроническим осложнением СД, ее диагностика и терапия оставляют желать лучшего. Для оптимизации подходов к диагностике и лечению болевой формы ДПН группой экспертов, представляющих ведущие российские профессиональные медицинские сообщества, были разработаны консенсусные клинические рекомендации по диагностике и рациональной терапии пациентов с болевой формой ДПН.

В данном документе представлены практические аспекты клинической диагностики болевой формы нейропатии и алгоритм дифференциальной диагностики болевого синдрома в нижних конечностях у больных СД. Руководствуясь основными аспектами патофизиологии нейропатической боли, обосновано применение симптоматических обезболивающих препаратов центрального действия - противосудорожных, антидепрессантов и опиоидов. Дана характеристика каждого класса препаратов, рассмотрены доказательные данные об эффективности, переносимости, а также возможности комбинированной терапии. Представлены данные о препаратах 1-й, 2-й и 3-й линии в соответствии с несколькими международными клиническими рекомендациями. Подчеркнута необходимость индивидуального подбора препарата с учетом доказательных данных по их эффективности и безопасности, сопутствующей медикаментозной терапии, переносимости, стоимости и предпочтений пациента, возраста больного и сопутствующих заболеваний.

КЛЮЧЕВЫЕ СЛОВА: сахарный диабет, диабетическая периферическая нейропатия, болевая нейропатия, нейропатическая боль, диагностика, лечение

\title{
DIAGNOSIS AND RATIONAL TREATMENT OF PAINFUL DIABETIC PERIPHERAL NEUROPATHY: AN INTERDISCIPLINARY EXPERT CONSENSUS
}

\author{
(c) Gagik R. Galstyan ${ }^{*}$, Elena G. Starostina², Nikolay N. Yakhno³, Irina V. Gurieva, Maxim V. Churukanov³, Igor A. Strokov³,
} Alla Y. Tokmakova', Mikhail L. Kukushkin ${ }^{5}$, Anatoly I. Martynov ${ }^{6}$, Marina V. Shestakova ${ }^{1}$

\section{'Endocrinology Research Centre, Moscow, Russia}

${ }^{2}$ Moscow Regional Research and Clinical Institute, Moscow, Russia

${ }^{3}$ I.M. Sechenov First Moscow State Medical University, Moscow, Russia

${ }^{4}$ Russian Medical Academy of Continuous Professional Education, Moscow, Russia

${ }^{5}$ Research Institute of General Pathology and Pathophysiology, Moscow, Russia

${ }^{6}$ A.I. Evdokimov Moscow State Medical Stomatological University, Moscow, Russia

Diabetic peripheral neuropathy is a common chronic complication of diabetes mellitus, significantly impairing well-being, quality of life and functioning of patients. The prevalence of diabetic peripheral neuropathy in the Russian Federation ranges from $0.1 \%$ to $67.2 \%$ in type 1 and from 0.1 to $42.4 \%$ in type 2 diabetes mellitus. However, based on the large-scale epidemiological studies, the true prevalence of diabetic peripheral neuropathy is much higher (50 to 70\%), with its painful variant occurring in $16 \%$ to $30 \%$ of patients. Despite the fact that diabetic peripheral neuropathy remains the most common chronic complication of diabetes mellitus, its diagnosis and therapy leave much to be desired. To optimize diagnostic and treatment approaches to painful diabetic peripheral neuropathy, a group of experts representing the leading Russian professional medical associations has developed clinical guidelines for the diagnosis and rational therapy of patients with painful diabetic peripheral neuropathy. 
This document presents practical aspects of the clinical diagnosis of painful diabetic peripheral neuropathy and an algorithm for differential diagnosis of pain in the lower extremities in patients with diabetes mellitus. The use of symptomatic analgesics with central action, such as anticonvulsants, antidepressants and opioids, is based on the main aspects of neuropathic pain pathophysiology. The characteristics of each drug class are given, with consideration of evidence on their efficacy, tolerability, and the possibility of combination therapy. The data on the first, second, and third lines of agents is presented in accordance with several international clinical guidelines. The need for a tailored drug choice, taking into account the evidence-based data on their efficacy and safety, concomitant drug therapy, tolerability, cost and preferences of the patient, age of the patient and concomitant disorders, is emphasized.

KEYWORDS: diabetes mellitus; diabetic peripheral neuropathy; painful neuropathy; neuropathic pain; diagnosis; treatment

Диабетическая периферическая нейропатия (ДПН) комплекс клинических и субклинических синдромов, каждый из которых характеризуется диффузным поражением периферических и/или автономных нервных волокон в результате сахарного диабета (СД).

Болевая форма ДПН (БДПН) серьезно ухудшает состояние, трудоспособность и качество жизни пациентов, способствует усилению тревоги, депрессии и нарушений сна, ухудшает физическое и психическое функционирование больных, снижая, в частности, их приверженность лечению, в том числе в отношении контроля гликемии. Наличие ДПН ассоциировано с ухудшением прогноза, повышением риска развития язв стопы и 15-кратным ростом риска ампутации нижних конечностей и инвалидизации. Кроме того, она является предиктором развития ретинопатии, нефропатии и повышенного риска смертности.

По данным Российского регистра СД, ДПН выявлена в среднем у 33,6\% больных СД 1 типа (СД1) и у 18,6\% больных СД 2 типа (СД2), причем эти показатели колеблются от 0,1\% до 67,2\% при СД1 и от 0,1 до 42,4\% при СД2 в зависимости от регионов РФ [1]. Однако, судя по широкомасштабным эпидемиологическим исследованиям, истинная распространенность ДПН гораздо выше (50-70\%), причем БДПН страдают от 16\% до более $30 \%$ пациентов. Таким образом, хотя ДПН остается самым распространенным хроническим осложнением СД, ее диагностика и, соответственно, лечение оставляют желать лучшего.

Несмотря на некоторые различия в классификациях ДПН и существование индивидуально сложных диагностических ситуаций, в большинстве случаев диагностика ДПН, особенно ее болевой формы, а также лечение без труда могут осуществляться не только неврологами, но и эндокринологами, о чем прямо говорится в основополагающем отечественном документе по ведению больных СД - «Алгоритмы специализированной медицинской помощи больным сахарным диабетом: клинические рекомендации» [2], а также, вне всякого сомнения, врачами общей практики и терапевтами. Это обусловлено тем, что диагноз данного состояния ставится на основании тщательно собранного анамнеза, внимательной оценки характера жалоб и физикального обследования нижних конечностей и в большинстве случаев практически не требует специальных методов диагностики.

В связи с этим, по мнению экспертов, представляющих ведущие российские профессиональные медицинские сообщества, назрела необходимость разработки клинических рекомендаций по диагностике и лечению пациентов с БДПН. Учитывая то важное обстоятельство, что В диагностике и лечении пациентов задействованы врачи различных специальностей, настоящие рекомен- дации созданы совместными усилиями экспертов, представляющих различные отрасли медицины.

Данный документ посвящен практическим аспектам диагностики, дифференциальной диагностики и симптоматической терапии БДПН и предназначен эндокринологам, диабетологам, неврологам, терапевтам, врачам общей практики и врачам любых специальностей, к которым могут обратиться пациенты с СД и жалобами на болевой синдром в ногах.

Классификация показаний к лечебным вмешательствам по степени доказательной эффективности

В течение последних двух десятилетий мировое сообщество использует следующую «Классификацию показаний к лечебным и диагностическим вмешательствам по степени доказательной эффективности» (табл. 1).

Определения и терминология: боль, виды боли,

нейропатическая боль

С позиций патофизиологии различают ноцицептивную и нейропатическую боль (НБ) [3-6]. Ноцицептивной называют боль, обусловленную воздействием какого-либо фактора (механическая травма, ожог, воспаление и т.д.) на периферические болевые рецепторы при интактности всех отделов нервной системы. Под нейропатической подразумевают боль, возникающую при органическом поражении или нарушении функции различных отделов соматосенсорной нервной системы. Причинами НБ могут быть повреждения нервной системы на любом уровне, начиная от периферических нервов и заканчивая корой больших полушарий.

НБ встречается у 6-10\% общей популяции [7-10]. Сегодня она объединяет целую группу хронических болевых синдромов, которые ранее рассматривались самостоятельно. К этой группе относят болевой синдром при различных моно- и полинейропатиях. Среди них наиболее часто боли возникают при диабетической и алкогольной полинейропатиях (25-45\%). Постгерпетическая невралгия (в пожилом возрасте это осложнение возникает в 70\% случаев опоясывающего герпеса) также является вариантом НБ. По данным разных авторов, частота НБ при диабетической полинейропатии достигает $45 \%$, рассеянном склерозе - 28\%, сирингомиелии - 75\%, мозговом инсульте - 8\%, травме нерва - 5\%. Среди всех пациентов с НБ около $50 \%$ составляют больные с ДПН. К сожалению, нередко боли у этих пациентов трактуются как сосудистые или вертеброгенные, что приводит к неадекватным терапевтическим мероприятиям.

НБ имеет некоторые особенности. Прежде всего, она сопровождается специфическими чувствительными расстройствами. Очень характерной для НБ является 
Таблица 1. Уровни доказательности

\begin{tabular}{|c|c|c|c|}
\hline $\begin{array}{c}\text { Градация } \\
\text { рекомендаций }\end{array}$ & дока & $\begin{array}{l}\text { нь } \\
\text { Вности }\end{array}$ & Источник \\
\hline \multirow{3}{*}{ A } & \multirow{3}{*}{1} & $1 a$ & $\begin{array}{c}\text { Систематические обзоры РКИ, выполненные на высоком методическом } \\
\text { уровне и с включением однородных групп пациентов }\end{array}$ \\
\hline & & $1 b$ & Отдельные РКИ, результаты которых имеют узкий доверительный интервал \\
\hline & & $1 c$ & $\begin{array}{c}\text { Отдельные РКИ, результаты которых имеют более широкий доверительный } \\
\text { интервал }\end{array}$ \\
\hline \multirow{3}{*}{ B } & \multirow{3}{*}{2} & $2 a$ & Систематические обзоры когортных исследований \\
\hline & & $2 b$ & $\begin{array}{c}\text { Отдельные когортные исследования, включающие исследования невысокого } \\
\text { методического уровня }\end{array}$ \\
\hline & & 2c & Неконтролируемые когортные исследования \\
\hline \multirow{2}{*}{$\mathrm{C}$} & \multirow{2}{*}{3} & $3 a$ & $\begin{array}{c}\text { Систематический обзор однотипных популяционных исследований } \\
\text { случай-контроль }\end{array}$ \\
\hline & & $3 b$ & Отдельные исследования случай-контроль \\
\hline $\mathrm{D}$ & 4 & & $\begin{array}{c}\text { Серии наблюдательных или отдельные когортные/популяционные } \\
\text { исследования невысокого методического уровня. }\end{array}$ \\
\hline $\mathrm{E}$ & 5 & & Мнение экспертов или лабораторные данные \\
\hline
\end{tabular}

аллодиния - появление боли в ответ на стимул, который в нормальных условиях не вызывает боли. В таких случаях больные испытывают сильные боли при малейшем прикосновении, иногда даже при дуновении ветра. Различают температурную и механическую аллодинию. Механическая аллодиния подразделяется на статическую, которая появляется при давлении на фиксированную точку кожного покрова, и динамическую, возникающую при движущихся стимулах, например, легком раздражении кожи кисточкой или пальцем.

При НБ часто наблюдаются гиперестезия, гипералгезия, гиперпатия, невралгия. При гипералгезии чувствительность к болевому стимулу оказывается значительно выше, чем ожидается в норме. При гиперпатии субъективный ответ как на болевой, так и неболевой стимулы является чрезмерным и часто сохраняется в течение долгого времени уже после прекращения раздражения. Пациента могут также беспокоить спонтанные боли, возникающие в отсутствие какого-либо очевидного внешнего воздействия. Они, как правило, носят жгучий, колющий характер. Чувство щекотания, безболезненного покалывания или другие подобные ощущения относятся к парестезиям; если эти ощущения причиняют боль, то их называют дизестезиями.

\section{Классификация диабетических нейропатий [11]}

В повседневной клинической практике чаще всего НБ в нижних конечностях у больных СД вызваны хронической сенсорной/сенсомоторной ДПН (около 80\%). Существенно меньший процент приходится на острые сенсорные, или атипичные, нейропатии - нейропатию Элленберга и острую «инсулиновую» нейропатию. Редкие формы болевых нейропатий при СД - проксимальная моторная нейропатия (синоним - диабетическая пояснично-крестцовая радикулоплексопатия) и другие фокальные и мультифокальные несимметричные ней- ропатии, поражающие периферические, черепно-мозговые и другие нервы, требуют направления к неврологу для специального обследования, дифференциальной диагностики и лечения.

\section{1. Диабетические нейропатии.}

\section{1. Диффузные нейропатии.}

1.1.1. Дистальная симметричная полинейропатия (ДСПН).

- Преимущественно с поражением волокон малого диаметра.

- Преимущественно с поражением волокон большого диаметра.

- Смешанное поражение волокон малого и большого диаметра.

1.1.2. Автономная.

1.1.2.1. Кардиоваскулярная.

- Снижение вариабельности сердечного ритма (ВСР).

- Тахикардия в покое.

- Ортостатическая гипотензия.

- Внезапная смерть (злокачественные нарушения ритма).

1.1.2.2. Желудочно-кишечная.

- Диабетический парез желудка (гастропатия).

- Диабетическая энтеропатия (диарея).

- Снижение моторики толстой кишки (запоры).

1.1.2.3. Урогенитальная.

- Диабетическая цистопатия (нейрогенный мочевой пузырь).

- Эректильная дисфункция.

- Сексуальная дисфункция у женщин.

1.1.2.4. Судомоторная дисфункция.

- Дистальный гипогидроз/ангидроз.

- рикулотемпоральный синдром. 
- Нарушение способности распознавать гипогликемию.

- Нарушение функции зрачка.

1.2. Мононейропатия (множественный мононеврит) (aтипичные формы).

1.2.1. Изолированное поражение черепных или периферических нервов.

1.2.2. Множественный мононеврит.

1.3. Радикулопатия или полирадикулопатия (атипичные формы).

1.3.1. Радикулоплексонейропатия.

1.3.2. Торакальная радикулопатия.

2. Недиабетические нейропатии, распространенные при сахарном диабете.

2.1. Компрессионный паралич.

2.2. Хроническая воспалительная демиелинизирующая полинейропатия.

2.3. Радикулоплексонейропатия.

2.4. Острая болевая нейропатия волокон малого диаметра (индуцированная лечением).

\section{Диабетическая периферическая нейропатия}

Диабетическая нейропатия - это наиболее распространенное хроническое осложнение СД, представляющее собой гетерогенную группу состояний, поражающих различные части нервной системы и представленных различными клиническими проявлениями [11]. Ранняя диагностика и должная тактика лечения нейропатии у пациентов с СД важны по многим причинам.

1. Диабетическая нейропатия - это диагноз исключения. У больных СД могут присутствовать недиабетические нейропатии, для лечения которых применяются специфические методы.

2. Существует несколько вариантов лечения симптомной ДПН.

3. До 50\% случаев ДПН протекают бессимптомно. В отсутствие своевременной диагностики и профилактического ухода за стопами пациенты находятся в группе риска повреждений нечувствительных стоп.

4. Среди различных форм диабетической нейропатии наиболее изученными являются дистальная симметричная полинейропатия и диабетическая автоном- ная полинейропатия, особенно кардиоваскулярная автономная нейропатия [11].

ДПН - это наиболее распространенная форма диабетической нейропатии; на ее долю приходится около 75\% всех диабетических нейропатий $[12,13]$. В клинической практике диагностика ДПН включает выявление симптомов и/или признаков дисфункции периферических нервов у пациентов с СД после исключения других причин.

ДПН развивается, как правило, не ранее чем через 5 лет от дебюта СД1, но к моменту постановки диагноза СД2 она уже может присутствовать, так как это заболевание часто протекает латентно и диагностируется поздно. ДПН начинается постепенно, как правило, со снижения чувствительности, которое иногда может не ощущаться пациентом или выявляется лишь тогда, когда больной с удивлением обнаруживает отсутствие боли при травмах или ожогах кожи или появляются язвы в местах наибольшего давления на стопе или нейропатическая остеоартропатия. Гораздо чаще пациенты жалуются на онемение, парестезии (покалывание, «ползание мурашек») и боли в ногах, которые они описывают как жгучие, стреляющие («как током»), режущие. Боли усиливаются ночью и несколько уменьшаются при ходьбе. Их интенсивность сильно варьирует у разных пациентов, и, как в целом принято считать, боль тем выше, чем больше в нейропатический процесс вовлечены тонкие нервные волокна. Поражение тонких нервных волокон также сопровождается гипералгезией (см. определение выше), в тяжелых случаях может иметь место аллодиния. Симптомы манифестируют с пальцев стоп, симметричны и постепенно распространяются по направлению снизу вверх на всю стопу, голень и более проксимальные отделы конечностей, в редких случаях - на верхние конечности (где они также вначале проявляются в пальцах и кистях) и передние отделы туловища. Однако такая динамика локализации неспецифична для ДПН и наблюдается также, например, при алкогольной и амилоидной полинейропатиях. По мере прогрессирования ДПН появляются моторные симптомы, в основном в виде слабости и постепенной атрофии мышц. Хроническая сенсорная ДПН - необратимое прогрессирующее осложнение.

Таблица 2. Основные клинические симптомы диабетической периферической нейропатии

\section{Симптомы}

Характер спонтанных болей

Провоцированные боли

Снижение чувствительности

Моторные симптомы

Сухожильные рефлексы

Синдром беспокойных ног

Начало

Течение

\section{Клинические проявления ДПН}

Интенсивность варьирует, но в целом менее выраженные, ломящие, простреливающие, режущие

Гипералгезия нередко, аллодиния реже

Снижение или потеря вибрационной, температурной, тактильной чувствительности

Могут иметься (шаткость походки, нарушение равновесия, слабость и атрофия мышц), но не обязательны

Могут снижаться или отсутствовать

Может быть

Постепенное

Длительное персистирование или усиление симптомов; возможно развитие язв стопы или остеоартропатии 


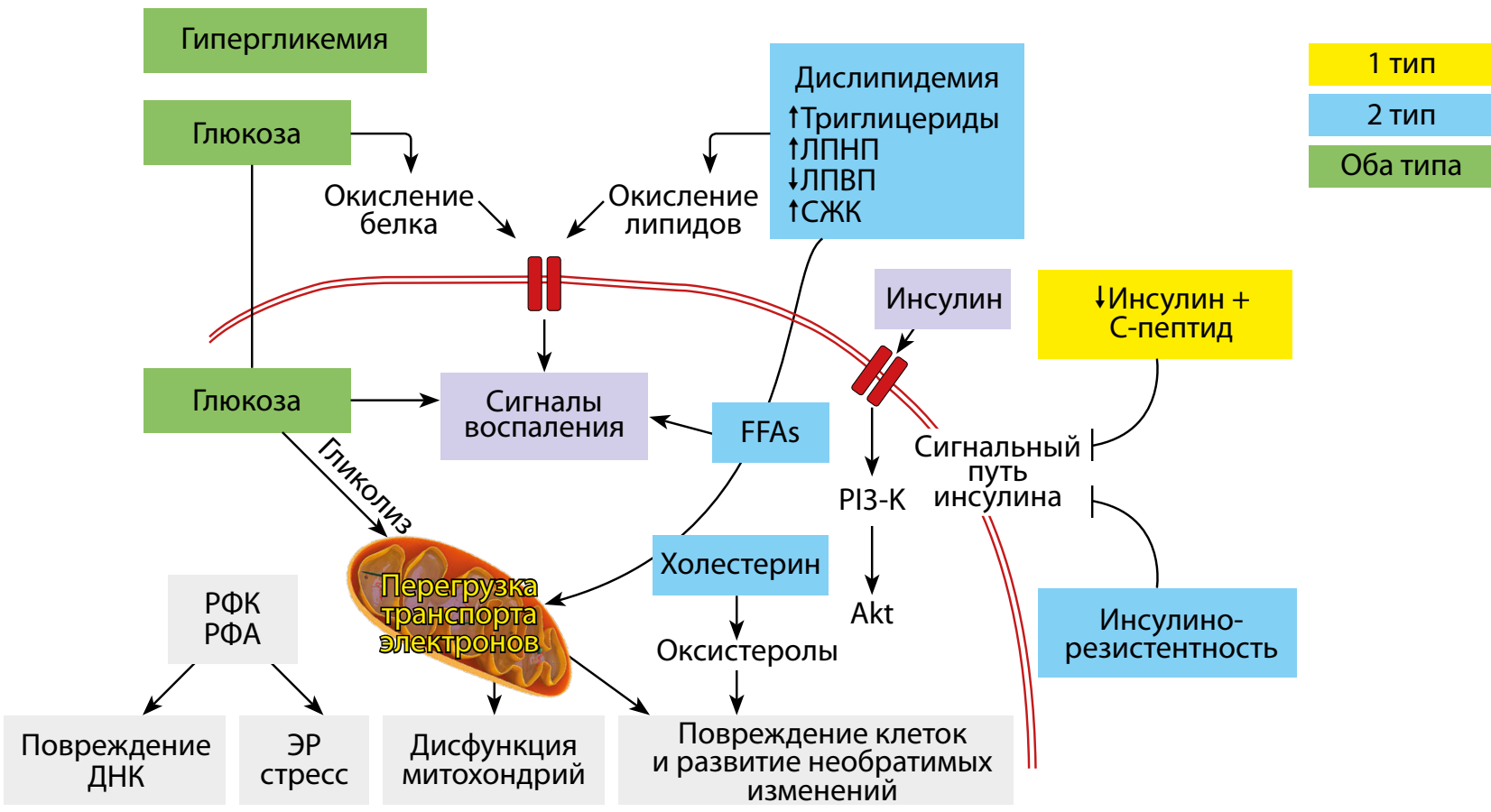

Рис. 1. Механизмы развития диабетической нейропатии. Факторы, характерные для сахарного диабета 1 типа (желтый цвет), сахарного диабета 2 типа (голубой цвет) и обоих типов заболевания (зеленый цвет), вызывают повреждение ДНК,

эндоплазматический ретикулярный стресс, нарушение функции митохондрий, повреждение клеток с развитием необратимых изменений. Относительная важность различных патогенетических механизмов варьирует в зависимости от типа клеток, профиля заболевания и времени. ЭР - эндоплазматический ретикулум; СЖК - свободные жирные кислоты; РІ3-К - фосфатидилинозитол-3-киназа; РФА - реактивные формы азота; РФК - реактивные формы кислорода. Адаптировано и воспроизведено из [11].

\section{ПАТОГЕНЕЗ ДИАБЕТИЧЕСКОЙ ПОЛИНЕЙРОПАТИИ}

Экспериментальные исследования свидетельствуют о многофакторном патогенезе ДПН (рис. 1), однако ее причины остаются неизвестными [14-16]. Поражение периферических нервов при СД обусловлено метаболическими нарушениями и микроангиопатией, вызванными хронической гипергликемией и сердечно-сосудистыми факторами риска.

В патогенезе всех форм ДПН как таковой участвуют взаимосвязанные и синергично действующие механизмы, триггером которых является гипергликемия. К ним относятся активация полиольного пути окисления глюкозы с внутриклеточным накоплением сорбитола и инозитола, гипоксия и ишемия нервов, усиление окислительного стресса, избыточная продукция конечных продуктов гликирования, липидные нарушения, включая дефицит гамма-линоленовой кислоты, повышение активности протеинкиназы С и других протеинкиназ, эндотелиальная дисфункция, дефицит инсулина и С-пептида, являющихся нейротрофическими факторами, активация поли-АДФ-рибозополимеразы (PARP).

\section{ПАТОГЕНЕЗ БОЛИ ПРИ ДИАБЕТИЧЕСКОЙ ПОЛИНЕЙРОПАТИИ}

НБ может присутствовать на любой стадии развития ДПН, от субклинической до тяжелых, далеко зашедших стадий в сочетании с остеоартропатией Шарко и нейропатически-инфицированными язвами стопы. Считается, что при БДПН поражены непокрытые миелином тонкие нервные волокна, причем изолированная или преимущественная сенсорная нейропатия тонких волокон может существовать при СД самостоятельно или пред- шествовать поражению толстых волокон. Однако объяснить болевой синдром исключительно поражением тонких волокон не удается - у определенного процента больных есть поражение тонких волокон, но нет боли, и наоборот. Парадоксальным остается и существование так называемой «болевой нечувствительной нейропатии» (англ. - «painful painless leg», или «болезненная безболевая нога»), при которой выраженный болевой синдром сочетается с полной утратой всех видов чувствительности в нижних конечностях.

Четких морфологических или функциональных различий периферических нервов у больных с БДПН и с безболевой ДПН не выявлено, кроме изменения плотности тонких волокон (внутрикожных и роговичных) при БДПН. Однако, какие именно механизмы отвечают за развитие БДПН, до конца неясно. Предположительно, генез любой НБ неспецифичен, сходен при разных заболеваниях, но даже разные механизмы могут вызвать одинаковые симптомы, и у одного и того же пациента таких механизмов может быть множество.

Не исключено, что гипергликемия как таковая может вызывать гипералгезию, независимо от структурного поражения нервов. Одним из возможных посредников в развитии повышенной болевой чувствительности служит метилглиоксаль - продукт неполного расщепления глюкозы, образующийся в цепочке реакций гликирования. Его уровни при БДПН выше, чем при ДПН без НБ, он модифицирует активность натриевого канала, участвующего в восприятии болевых стимулов, вызывая гипералгезию на тепловые и механические раздражители. За последние годы важную роль в генезе БДПН стали отводить иммунным клеткам, микроглии и нейронам ЦНС. Так, клетки микроглии спинного мозга в условиях гипергликемии активируются, вырабатывают большое ко- 
личество провоспалительных цитокинов, которые могут индуцировать и поддерживать нейропатическую боль; повышение концентрации провоспалительных цитокинов и фактора некроза опухоли-а при БДПН (но не при ДПН без НБ) обнаружено в макрофагах. Определенную роль играет и поражение микроциркуляторного русла, снабжающего кровью нервные стволы (vasa nervorum): так, при острой инсулиновой нейропатии отмечаются изменения этих микрососудов, близкие к таковым при пролиферативной ретинопатии, с резким повышением проницаемости и нарушением микроархитектоники.

При БДПН задействованы две группы механизмов повышения чувствительности к боли - периферическая сенситизация и центральная сенситизация. Периферическая сенситизация - снижение порога чувствительности периферических окончаний нервов, отвечающих за рецепцию боли, в ответ на воздействие медиаторов воспаления и других перечисленных веществ, продукция которых усиливается при гипергликемии. Вследствие этого воздействие слабых болевых раздражителей может восприниматься гораздо сильнее (гипералгезия), а неболевых раздражителей - как болевое (аллодиния). Центральная сенситизация обусловлена повышением нейрональной активности и расширением рецепторных полей в спинном мозге, таламусе и сенсорной коре, что также ведет к усилению центральной перцепции боли и ее генерализации, следовательно, к усилению ощущения спонтанных болей, гипералгезии и аллодинии.

\section{СКРИНИНГ И ДИАГНОСТИКА ДПН}

Ежегодную оценку симптомов и признаков ДПН на основании сбора анамнеза и простых клинических тестов необходимо выполнять у всех пациентов с СД1 при длительности заболевания $\geq 5$ лет и у всех пациентов с СД2 (табл. 3).

Жалобы со стороны нижних конечностей присутствуют почти у 50\% пациентов с ДПН, в то время как у остальных она протекает бессимптомно. Больные могут сами не предъявлять жалоб, однако при активном опросе указывают на наличие онемения или других симптомов ДПН.
Выявление БДПН у пациентов с СД должно носить активный характер и быть неотъемлемой частью сбора жалоб и анамнеза с уточнением наличия и характера боли.

БДПН имеет ряд клинических особенностей и характеризуется полиморфизмом болевых ощущений. Симптомы могут варьировать в зависимости от того, какой класс волокон вовлечен в патологический процесс. Наиболее частыми ранними симптомами, вызванными вовлечением волокон малого диаметра, являются боль и дизестезии (неприятные ощущения или жжение) [17-19]. НБ может быть первым симптомом, побуждающим пациента обратиться к врачу, и присутствуют почти у $25 \%$ лиц с ДПН [20-22]. Боли носят жгучий, режущий, покалывающий или стреляющий характер (как разряд электрического тока); сопровождаются парестезиями; присутствуют в различных комбинациях; их выраженность обычно усиливается по ночам. НБ может сопровождаться повышением ответа на болевые стимулы (гипералгезия) и болями, провоцируемыми контактом (с носками, обувью и постельным бельем; аллодиния). НБ может оказывать негативное влияние на повседневную активность, приводить к инвалидизации, психологическим нарушениям и снижать качество жизни, связанное с состоянием здоровья [23-25].

Боль может быть спонтанной или носить стимулзависимый характер. Спонтанная боль может быть постоянной или пароксизмальной - описываться как жгучая, стреляющая, сдавливающая, пекущая, мозжащая, скручивающая, холодящая и др. В области болезненных ощущений, как правило, выявляются расстройства тактильной, болевой и/или температурной чувствительности. Среди спонтанных ощущений отмечаются парестезии, описываемые как ощущения покалывания или ползания мурашек, дизестезии - извращенное восприятие раздражения, гиперпатия - усиленное восприятие стимула, снижение или повышение болевой и температурной чувствительности - гипо-, гиперестезия. Стимулзависимая боль, возникающая в ответ на легкое механическое раздражение при обследовании кисточкой либо в повседневной жизни бельем, одеждой или дуновением воздуха, носит название аллодинии.

Таблица 3. Рекомендации по проведению скрининга и диагностики диабетической периферической нейропатии

\section{Основные положения}

Уровень

доказательности

Всем пациентам необходимо выполнять оценку признаков и симптомов ДПН на момент установления диагноза СД2 и каждые 5 лет после установления диагноза СД1, с последующим ежегодным обследованием.

Рассмотреть показания к скринингу у пациентов с предиабетом (НТГ, НГН) при наличии у них симптомов периферической нейропатии.

Оценка симптомов должна включать тщательный сбор анамнеза и исследование температурной или болевой чувствительности и вибрационной чувствительности с использованием камертона 128 Гц (функция волокон большого диаметра). Всем пациентам необходимо выполнять ежегодное исследование с использованием монофиламента весом 10 г для оценки риска развития язв стопы и ампутации.

Электрофизиологическое исследование или направление к неврологу редко показано на этапе скрининга, за исключением ситуаций наличия атипичных клинических признаков, неясного диагноза или подозрения на иную этиологию заболевания. Атипичные признаки включают бо́льшую выраженность моторной нейропатии по сравнению с сенсорной, быстрое начало или асимметричную выраженность симптомов. 
О вовлечении волокон большого диаметра может свидетельствовать чувство онемения, покалывания без болевого синдрома и утраты протективной чувствительности. Потеря протективной чувствительности является фактором риска образования диабетических язв стопы. Пациенты часто описывают свои ощущения, как будто стопа обернута шерстью или одета в толстые носки. Это свидетельствует о потере способности чувствовать боль и позволяет пациентам с нейропатическими язвами подошвенной поверхности стопы ходить при наличии повреждений, что приводит к хронизации процесса, зачастую осложняющегося инфекцией [26].

В зоне боли могут наблюдаться трофические изменения кожи, подкожной клетчатки, волос, ногтей, нарушение мышечного тонуса или локальные вегетативные расстройства, связанные с одновременным поражением вегетативных волокон в составе периферических нервов.

Данные количественного сенсорного тестирования с использованием контролируемых физиологических стимулов, таких как температура, давление, укол и вибрация, используются для точной верификации чувствительных нарушений при НБ.

Для оценки вибрационной чувствительности может использоваться камертон с частотой 128 Гц. Вибрационная чувствительность, как правило, нарушается раньше, чем тактильная, болевая, позиционная и температурная, и гораздо раньше, чем появляются моторные симптомы в виде мышечной слабости. Снижение вибрационной чувствительности ниже возрастной границы нормы служит надежным, простым и удобным скрининговым тестом для диагностики ДПН. В ряде случаев, особенно при СД2, нарушение вибрационной чувствительности идет параллельно с повышением порогов к термическим раздражителям; такие пациенты нередко получают ожоги при «распаривании» ног, так как они не чувствуют высокой температуры воды.

Оценка тактильной чувствительности с использованием монофиламента весом 10 г проводится на дорсальной поверхности первого пальца стопы [27]. Монофиламент весом 10 г - это полезный инструмент для клинической диагностики, используемый главным образом для выявления прогрессирующих стадий нейропатии и идентификации пациентов группы повышенного риска по развитию язв и ампутации [28]. Тест с монофиламентом 10 г, включенный в программу ежегодного скрининга и диагностики ДПН, отличается от теста для диагностики «стопы высокого риска» в плане развития язВ - позднего осложнения ДПН и требует исследования 4 областей (головки I, III и V плюсневых костей и подошвенная поверхность дистального сегмента большого пальца стопы) на каждой стопе [29].

Более тонкие методы оценки различных видов чувствительности могут быть использованы у пациентов с НБ, когда поражение трудно выявить по данным клинического обследования, для исключения других причин боли и изучения механизмов развития болевого синдрома. Как правило, для диагностики в повседневной клинической практике они не требуются.

В целом диагноз ДПН и БДПН является преимущественно клиническим. Сочетания типичных жалоб на болевые ощущения и симметричных нарушений чувствительности обычно достаточно для постановки диагноза
БДПН. у пациента с СД с большой степенью вероятности свидетельствуют о наличии ДПН и могут не требовать дополнительного обследования или направления к специалисту.

Шкалы для скрининга и диагностики нейропатической боли

Для облегчения идентификации НБ были разработаны скрининговые шкалы: Лидсская шкала оценки нейропатических симптомов и признаков (LANSS), диагностический опросник НБ 4 (DN4), Опросник нейропатической боли, Опросник для выявления боли (Pain DETECT), опросник стандартизованной оценки боли (StEP), ID Pain, и др. Каждая шкала характеризует НБ по констатации позитивных и негативных симптомов и знаков, включающих спонтанную боль, парестезии, дизестезии, аллодинию, двигательный и чувствительный дефект. Учитывая важность определения наличия НБ для дальнейшего лечения, обязательны надежность, валидность и диагностическая точность подобных шкал. В настоящее время одним из самых чувствительных в отношении выявления НБ является опросник DN4 (рис. 2).

При положительном ответе на 4 и более вопросов из 10 пунктов этого опросника диагноз «нейропатическая боль» обоснован. Чувствительность методики DN4 (количество пациентов с НБ, у которых выявляется эта патология по результатам тестирования) составляет $80 \%$. Это позволяет использовать ее в качестве скрининга для выявления НБ различного генеза, в том числе при БДПН; специфичность опросника не является столь высокой.

\begin{tabular}{lc}
\hline Собеседование с пациентом & Да $\quad$ Нет \\
\hline Соответствует ли боль, которую испытывает пациент, \\
одному или нескольким из следующих определений? \\
1. Ощущение жжения \\
2. Болезненное ощущение холода \\
3. Время от времени
\end{tabular}

Сопровождается ли боль одним или несколькими из следующих симптомов в области ее локализации?

4. Пощипыванием, ощущением ползания мурашек

5. Покалыванием

6. Онемением

7. Зудом

Осмотр пациента

Да Нет

Локализована ли боль в той же области, где осмотр выявляет один или оба следующих симптома:

8. Пониженная чувствительность к прикосновению

9. Пониженная чувствительность к покалыванию

Можно ли вызвать или усилить боль в области ее локализации:

10. Проведя в этой области кисточкой

Рис. 2. Опросник DN4. 
Атипичная острая диабетическая нейропатия

Атипичная БДПН встречается значительно реже и в значительной мере отличается от типичной формы по патофизиологическим механизмам развития, течению и клинической манифестации [30, 31]. Развитие и манифестация атипичной БДПН возможны при любой продолжительности СД [31]. Симптоматика атипичной ДПН может возникнуть как остро, так и носить хронический характер; возможны варианты как с монофазным вариантом течения, так и с волнообразным. Для атипичной ДПН характерно наличие болевой симптоматики и автономной дисфункции [30].

Однозначных критериев диагностики и определения тяжести течения атипичных форм БДПН в настоящее время нет. Характерным случаем, в котором следует заподозрить атипичный вариант БДПН, является наличие НБ и/или признаков автономной дисфункции в сочетании с нормальными результатами оценки нервной проводимости и вибрационной чувствительности. В основе атипичной картины БДПН лежит нейропатия тонких волокон.

Для диагностики поражения немиелинизированных и слабомиелинизированных нервных волокон малого калибра используются различные диагностические тесты и инструменты: количественное сенсорное тестирование температурной/болевой чувствительности, биопсия кожи с исследованием тонких волокон, оценка функции потовых желез, лазерная допплеровская флоуметрия, конфокальная микроскопия роговицы.

В случае отсутствия изменений нервной проводимости при электронейромиографии (ЭНМГ) диагноз атипичной ДПН может быть подтвержден исследованием интраэпидермальной плотности нервных волокон в коже голени (уровень доказательств класса A), либо количественным сенсорным тестированием температурной чувствительности на стопах, либо конфокальной микроскопией роговицы, хотя изучение распределения тонких нервов в роговице является только косвенным параметром, отражающим их состояние в конечностях.

Диагноз атипичной БДПН с поражением тонких сенсорных волокон может быть установлен на основании нижеперечисленных критериев [32]:

1. диагноз возможен: присутствие типичной дистальной нейропатической симптоматики и/или клинические признаки поражения тонких сенсорных волокон;

2. диагноз вероятен: присутствие типичной дистальной нейропатической симптоматики, клинические признаки поражения тонких сенсорных волокон и нормальная проводимость по n. suralis;

3. диагноз подтвержден: присутствие типичной дистальной нейропатической симптоматики, клинические признаки поражения тонких сенсорныхволокон, нормальная проводимость по $n$. suralis и положительные результаты биопсии кожи голеней (снижение интраэпидермальной плотности нервных волокон) и/или изменения при количественном тестировании температурной чувствительности на стопах.

Нейропатия, индуцированная лечением (TIND treatment induced diabetic neuropathy) $[33,34]$ в последние годы привлекает внимание и, по-видимому, встречается чаще, чем это было принято считать ранее до 10\% в медицинских центрах третичного уровня. Эту форму нейропатии также называют «острым инсулино- вым невритом», или обратимой болевой автономной нейропатией. «Диабетическая кахексия», описанная Элленбергом в 1973 г., по-видимому, является одним из ее симптомов, а в ряде случаев - патогенетическим механизмом (возможный дефицит микроэлементов или витаминов), на фоне чего могут развиваться болевая симптоматика и автономная дисфункция.

Для этой формы БДПН, которая может встречаться как при СД1, так и при СД2, характерны более выраженная и рефрактерная к лечению боль, у ряда больных достигающая 10 баллов по 10-балльной рейтинговой шкале. Боль является симметричной и дистальной, однако у трети больных носит генерализованный характер, распространяясь на туловище и верхние конечности.

У всех больных боль возникает остро, как правило, через 6-8 нед после быстрого снижения глюкозы крови после предшествующего периода неудовлетворительного гликемического контроля. Аллодиния отмечается при СД1 в 60\%, при СД2 - в 40\% случаев, что гораздо чаще, чем при типичной сенсомоторной форме БДПН. Вегетативные расстройства присутствуют в виде кардиальной симптоматики, нарушений вариативности сердечного ритма, падения систолического АД, желудочно-кишечных нарушений, мальабсорбции. Отмечена корреляция TIND с прогрессивным развитием диабетической ретинопатии, наблюдающейся при резком снижении глюкозы крови. Отмечено, что фактором риска развития острой болевой и автономной дисфункции является снижение $\mathrm{HbA}_{1 с}$ более чем на 2\% за 3 мес; при снижении $\mathrm{HbA}_{1}$ с более чем на 4\% за 3 мес риск TIND составляет $80 \%$.

Патогенез этой формы нейропатии остается не до конца ясным. Среди возможных механизмов развития рассматриваются: эпиневральное артерио-венозное шунтирование, приводящее к эндоневральной ишемии; невральный апоптоз из-за внезапного падения глюкозы крови; рецидивирующие гипогликемии, приводящие к повреждениям микрососудистого кровоснабжения; эктопические болевые сигналы от регенерирующих нервов (наиболее вероятно, вследствие нарушения экспрессии ионных каналов или их рецепторов); инсулин-индуцированное снижение парциального давления кислорода в тканях вследствие развития артерио-венозного шунтирования. Кроме перечисленных механизмов, возможно влияние активного воспаления, так как при болевой острой нейропатии происходит особо значимое повышение уровней провоспалительных цитокинов (ИЛ-6, ФНО-альфа). Морфологически наблюдаются значительный отек тонких нервных волокон и уменьшение плотности тонких нервных волокон в коже. Изменения обратимы больше при СД1, чем при СД2, но и при СД2 нарушения также претерпевают обратное развитие, хотя с меньшими темпами. Полагают, что термин «нейропатия, индуцированная лечением» более адекватно отражает суть процесса в нерве, чем термин «инсулиновый неврит» [33].

Лечение острой болевой автономной нейропатии и «диабетической кахексии» - сложная задача ввиду рефрактерности боли к лечению. Необходимо улучшение контроля глюкозы, особенно важно снижение чрезмерных суточных колебаний ее уровня. Для облегчения боли используются те же препараты, которые представлены в разделе «Лечение»; в ряде случаев проводится коррекция дефицита витаминов, особенно B и D. 
Прогноз обычно благоприятный, и болевая симптоматика разрешается через 12-18 мес. Возможно наличие резидуальной или сопутствующей сенсомоторной дисфункции, а также рецидивов болевой симптоматики.

\section{ДИФФЕРЕНЦИАЛЬНАЯ ДИАГНОСТИКА БДПН С ДРУГИМИ НЕЙРОПАТИЯМИ И С БОЛЯМИ В НИЖНИХ КОНЕЧНОСТЯХ ДРУГОЙ ЭТИОЛОГИИ}

БДПН - диагноз исключения. у больных СД могут иметься и недиабетические болевые нейропатии, этиопатогенез которых не связан с СД [34]. К возможным этиологическим факторам недиабетических болевых нейропатий относятся интоксикации (чаще всего злоупотребление алкоголем, реже - отравление свинцом, ртутью), онкологические заболевания (классический пример заболевания, часто сопровождающегося полинейропатией, бронхогенный рак легкого), инфекции (ВИЧ, герпес и др.), дефицит витаминов $\mathrm{B}_{12}, \mathrm{~B}_{6}$ и $\mathrm{B}_{1}$, амилоидоз, применение некоторых лекарств средств (изониазида, алкалоидов барвинка, противоопухолевых средств, антиретровирусных препаратов). Большинство этих причинных факторов несложно установить или предположить путем тщательного сбора анамнеза и диагностики сопутствующих заболеваний у конкретного пациента. По нашим наблюдениям, если симптомы болевой полинейропатии выявляются у молодых пациентов с СД1 длительностью до 5 лет и тем более впервые выявленным, то в первую очередь следует думать об алкогольной нейропатии, тем более, что распространенность злоупотребления алкоголем среди подростков и молодых взрослых довольно высока [34].

В рутинной клинической практике очень часто приходится дифференцировать болевой синдром, обусловленный ДПН, от болей в ногах, вызванных другой патологией. Как правило, больной СД на приеме предъявляет жалобы просто на «боли в ногах», не конкретизируя их. В табл. 4 представлены заболевания, сопровождающиеся болями в ногах и часто встречающиеся у больных СД. Опрашивая и осматривая пациента в соответствии с предложенными пунктами (см. колонку «Признак»), в большинстве случаев можно достаточно быстро и надежно установить причину болевого синдрома. Диагностическая задача усложняется тем, что у многих больных СД встречается сочетание указанных в таблице видов патологии, например, чаще всего - комбинация нейропатического и ишемического характера поражения нижних конечностей. Тем не менее детальный расспрос и внимательное физикальное обследование и здесь помогают дифференцировать нейропатический и ишемический компонент болевого синдрома.

Особенно необходима высокая настороженность практических врачей в отношении депрессивных расстройств как возможной причины болевого синдрома. Распространенность депрессии у больных СД достигает 20-30\%, при этом главными жалобами 45-95\% пациентов являются различного рода соматические, включая болевые, синдромы, в частности боли в ногах.

\section{СОВРЕМЕННЫЕ ПОДХОДЫ К ПРОФИЛАКТИКЕ ДИАБЕТИЧЕСКОЙ ПЕРИФЕРИЧЕСКОЙ НЕЙРОПАТИИ}

Профилактика ДПН основана на коррекции факторов риска ее развития.
Факторы риска развития диабетической

периферической нейропатии

В исследовании осложнений при СД1 (EURODIAB) было показано, что вероятность развития ДПН статистически значимо повышается при артериальной гипертонии (относительный риск [OP] 1,5), большой длительности СД (ОР 1,4), гипергликемии и ее колебаниях (ОР 1,4 и 1,3, соответственно), курении (ОР 1,3), ожирении (OP 1,2) и гипертриглицеридемии (OP 1,2). Можно ли повлиять на ДПН путем воздействия на эти факторы риска?

При СД1 достижение близкого к нормальному уровня гликемии снижает риск развития микроангиопатии и нейропатии, но не может полностью исключить ее возникновение или значительно уменьшить симптомы. При СД2 достижение нормогликемии практически не влияет на профилактику или торможение ДПН и БДПН.

Хотя качественные клинические исследования по оценке роли адекватного контроля АД, дислипидемии, отказа от курения в профилактике и лечении ДПН не проводились, большинство экспертов сходятся во мнении, что достижение целевого АД, контроль уровня липидов (особенно триглицеридов), отказ от курения и употребления алкоголя могут оказать определенный положительный эффект в отношении ДПН.

\section{Контроль гликемии}

Интенсивный контроль гликемии у пациентов с СД1 способствовал резкому уменьшению частоты ДПН (уменьшение ОР на 78\%) [35-37]. Напротив, у пациентов с СД2 интенсивный контроль гликемии ассоциировался лишь с умеренным снижением риска развития ДПН (уменьшение ОР на 5-9\%) [38, 39]. В небольшом исследовании у пациентов с ранними стадиями СД2, выполненном в Японии, интенсифицированная инсулинотерапия сопровождалась улучшением отдельных параметров оценки ДПН [40], а в исследовании ACCORD (Мероприятия для контроля сердечно-сосудистого риска при сахарном диабете) было показано умеренное, но значимое снижение риска развития сенсорной ДПН на фоне контроля гликемии у пациентов с СД2 по истечении 5 лет наблюдения [41]. Другие масштабные исследования не продемонстрировали какого-либо эффекта [42-44]. Это несоответствие подчеркивает различия между СД1 и СД2 и свидетельствует о том, что у многих пациентов с СД2 ДПН развивается, несмотря на адекватный контроль гликемии. Наличие многочисленных сопутствующих заболеваний, полипрагмазия, гипогликемия и набор массы тела могли ослаблять эффекты контроля гликемии в этих исследованиях и объяснять несогласованность их результатов. Специфические стратегии снижения уровня гликемии также могут обусловливать эти разногласия. Например, у участников, особенно у мужчин, исследования BARI 2D (изучение шунтирующей ангиопластики у пациентов с СД2), получавших препараты, повышающие чувствительность периферических тканей к инсулину (сенситайзеры инсулина), была отмечена меньшая частота сенсорной ДПН через 4 года по сравнению с участниками, получавшими инсулин/препараты сульфонилмочевины [45]. Полученные результаты могут объясняться меньшим увеличением массы тела и меньшей частотой гипогликемии. Наконец, тот факт, что у многих пациентов присутствует бессимптомная гипергликемия в течение многих лет 
Таблица 4. Клинический дифференциальный диагноз болей в нижних конечностях [34].

\begin{tabular}{|c|c|c|c|c|c|}
\hline Признак & $\begin{array}{c}\text { Диабетическая } \\
\text { нейропатия }\end{array}$ & $\begin{array}{c}\text { Облитерирующий } \\
\text { атеросклероз }\end{array}$ & $\begin{array}{c}\text { Хроническая } \\
\text { венозная } \\
\text { недостаточность }\end{array}$ & $\begin{array}{l}\text { Болезни } \\
\text { суставов }\end{array}$ & Депрессия \\
\hline $\begin{array}{l}\text { Локализация } \\
\text { боли }\end{array}$ & $\begin{array}{l}\text { Стопы болят } \\
\text { больше, } \\
\text { чем голени; } \\
\text { голени болят } \\
\text { больше, } \\
\text { чем бедра }\end{array}$ & $\begin{array}{c}\text { Голени, бедра } \\
\text { болят больше, } \\
\text { чем стопы }\end{array}$ & $\begin{array}{c}\text { Преимущественно } \\
\text { голени }\end{array}$ & $\begin{array}{c}\text { Боли в области } \\
\text { суставов }\end{array}$ & $\begin{array}{c}\text { Четкой } \\
\text { локализации } \\
\text { нет; помимо } \\
\text { болей в ногах, } \\
\text { могут иметься } \\
\text { боли другой } \\
\text { локализации } \\
\text { (голова, спина) }\end{array}$ \\
\hline $\begin{array}{l}\text { Характер } \\
\text { боли }\end{array}$ & $\begin{array}{c}\text { Острые, жгучие, } \\
\text { стреляющие, } \\
\text { режущие, } \\
\text { «поверхностные», } \\
\text { реже глубокие }\end{array}$ & $\begin{array}{l}\text { Глубокие, } \\
\text { ломящие }\end{array}$ & Распирающие & $\begin{array}{l}\text { Острые или } \\
\text { ноющие }\end{array}$ & $\begin{array}{l}\text { Непостоянные, } \\
\text { мигрирующие }\end{array}$ \\
\hline Боли в покое & Присутствуют & $\begin{array}{c}\text { Редко (только } \\
\text { при крайней } \\
\text { степени ишемии) }\end{array}$ & $\begin{array}{c}\text { Отсутствуют или } \\
\text { быстро проходят } \\
\text { в положении } \\
\text { лежа или с } \\
\text { приподнятыми } \\
\text { ногами }\end{array}$ & $\begin{array}{c}\text { Уменьшаются, } \\
\text { не изменяются } \\
\text { или отсутствуют }\end{array}$ & $\begin{array}{c}\text { Обычно } \\
\text { воспринимаются } \\
\text { сильнее }\end{array}$ \\
\hline $\begin{array}{l}\text { Боли при } \\
\text { ходьбе }\end{array}$ & Уменьшаются & $\begin{array}{c}\text { Усиливаются } \\
\text { («синдром } \\
\text { перемежающейся } \\
\text { хромоты») }\end{array}$ & $\begin{array}{c}\text { Возникают не } \\
\text { сразу, усиливаются } \\
\text { к вечеру }\end{array}$ & $\begin{array}{c}\text { Практически } \\
\text { постоянно }\end{array}$ & $\begin{array}{c}\text { Обычно менее } \\
\text { заметны }\end{array}$ \\
\hline Боли ночью & Усиливаются & $\begin{array}{c}\text { Отсутствуют } \\
\text { (кроме крайних } \\
\text { степеней ишемии) }\end{array}$ & Отсутствуют & $\begin{array}{c}\text { Не зависят } \\
\text { от времени суток }\end{array}$ & $\begin{array}{c}\text { Не зависят } \\
\text { от времени суток }\end{array}$ \\
\hline Кожа & $\begin{array}{c}\text { Теплая, влажная, } \\
\text { реже сухая } \\
\text { с гиперкератозами }\end{array}$ & $\begin{array}{l}\text { Холодная, } \\
\text { бледная, } \\
\text { сухая }\end{array}$ & $\begin{array}{c}\text { Теплая, обычной } \\
\text { влажности }\end{array}$ & $\begin{array}{c}\text { Теплая, над } \\
\text { суставами может } \\
\text { быть горячей }\end{array}$ & Без изменений \\
\hline Сосуды & $\begin{array}{c}\text { Капиллярная } \\
\text { сеть расширена; } \\
\text { подкожные вены } \\
\text { полнокровны; } \\
\text { пульсация } \\
\text { артерий стопы } \\
\text { хорошая }\end{array}$ & $\begin{array}{c}\text { Пульсация } \\
\text { артерий стопы } \\
\text { ослаблена или } \\
\text { отсутствует; } \\
\text { снижение или } \\
\text { отсутствие } \\
\text { пульсации выше- } \\
\text { расположенных } \\
\text { артерий }\end{array}$ & $\begin{array}{c}\text { Расширенные, } \\
\text { варикозно } \\
\text { измененные вены; } \\
\text { возможны } \\
\text { явления } \\
\text { тромбофлебита }\end{array}$ & $\begin{array}{c}\text { Без } \\
\text { патологических } \\
\text { изменений }\end{array}$ & $\begin{array}{c}\text { Без } \\
\text { патологических } \\
\text { изменений }\end{array}$ \\
\hline Отеки ног & Нет & Нет & Есть & $\begin{array}{c}\text { Локальные в } \\
\text { области сустава }\end{array}$ & Нет \\
\hline $\begin{array}{l}\text { Локализация } \\
\text { язв }\end{array}$ & $\begin{array}{c}\text { Места } \\
\text { наибольшего } \\
\text { давления на стопе: } \\
\text { подошва } \\
\text { (пятка, плюсна) }\end{array}$ & $\begin{array}{l}\text { Кончики } \\
\text { пальцев }\end{array}$ & Голень & Отсутствуют & Отсутствуют \\
\hline $\begin{array}{l}\text { Объем } \\
\text { движений }\end{array}$ & Сохранен & Сохранен & Сохранен & $\begin{array}{c}\text { Уменьшен } \\
\text { или ограничен }\end{array}$ & Сохранен \\
\hline $\begin{array}{l}\text { Вибрационная } \\
\text { чувствитель- } \\
\text { ность }\end{array}$ & $\begin{array}{c}\text { При хронической } \\
\text { форме снижена, } \\
\text { при острой } \\
\text { сенсорной } \\
\text { нейропатии может } \\
\text { быть не изменена }\end{array}$ & $\begin{array}{c}\text { Как правило, } \\
\text { сохранена }\end{array}$ & Сохранена & Сохранена & Сохранена \\
\hline
\end{tabular}




\section{Основные положения}

Уровень

доказательности

Оптимизировать контроль гликемии на как можно более ранних этапах для профилактики или отсрочки развития дистальной симметричной полинейропатии и кардиоваскулярной автономной нейропатии у пациентов с СД1.

Оптимизировать контроль гликемии для профилактики или замедления прогрессирования дистальной симметричной полинейропатии у пациентов с СД2.

Рассмотреть возможность мультидисциплинарного подхода, предусматривающего контроль гликемии среди других факторов риска, для профилактики кардиоваскулярной автономной нейропатии у пациентов с СД2.

до диагностики СД2, может также ограничивать преимущества этих пациентов. Рекомендации по контролю гликемии для профилактики ДПН даны в табл. 5.

\section{Изменение образа жизни}

На сегодняшний день наилучшая, основанная на доказательствах модель интенсивного изменения образа жизни была разработана в рамках Программы профилактики диабета в исследовании Steno-2 [46], исследовании итальянских коллег на беговой дорожке под контролем [47] и исследовании у пациентов с СД2, выполненном в Университете Юты [48]. Последнее исследование продемонстрировало регенерацию нервных волокон у пациентов с СД2 на фоне программы физических упражнений по сравнению с утратой нервных волокон у пациентов, которым проводили только стандартную терапию.

В целом такой подход фокусируется либо только на физических упражнениях (аэробные и/или силовые тренировки под контролем), либо на комбинации модификации питания и физической активности. Консенсуса относительно пищевых режимов не существует, хотя в исследовании DPP использовали низкокалорийную диету, бедную жирами, а в других исследованиях были показаны преимущества применения средиземноморской диеты, характеризующейся несколько меньшей долей углеводов (45\%) и более высокой долей жиров (35-40\%), при этом доля насыщенных жиров не превышает $10 \%$.

Хотя исследования DPP [49] и «Нейропатия при нарушении толерантности к глюкозе» [50] показали положительное влияние изменения образа жизни на развитие
ДПН, эти исследования не включали пациентов с установленным диагнозом СД. Рекомендации по изменению образа жизни даны в таблице 6.

\section{КОМПЕТЕНЦИИ СПЕЦИАЛИСТОВ В ВЕДЕНИИ ПАЦИЕНТОВ С БОЛЕВОЙ ДИАБЕТИЧЕСКОЙ ПЕРИФЕРИЧЕСКОЙ НЕЙРОПАТИЕЙ}

Больной СД с ДПН требует комплексного и дифференцированного подхода в лечении и обследовании с участием терапевта (врача общей практики), эндокринолога и невролога.

В задачи терапевта и врача общей практики входит тщательный сбор анамнеза, клиническое обследование пациента и лабораторная диагностика, направленные на установку диагноза СД и выявление нейропатического характера боли. В ходе сбора анамнеза обязательно активное уточнение наличия, характера и локализации боли. Такие характеристики боли, как жжение, покалывание, зуд, онемение, ползание мурашек и др., требуют использования опросника DN4 для верификации нейропатического характера боли. В задачи терапевта и врача общей практики также входит первичное назначение терапии СД и БДПН.

Назначение или коррекция терапии СД и БДПН входят и в задачи эндокринолога.

При необходимости, в случае неэффективности лечения, для уточнения характера поражения нервной системы, при наличии признаков атипичной формы ДПН пациент должен быть направлен к неврологу для дополнительного обследования и коррекции терапии НБ (рис. 3).

Таблица 6. Профилактика развития диабетической периферической нейропатии

\section{Основные положения}

Уровень

доказательности

Для профилактики дистальной полинейропатии

у пациентов с предиабетом/метаболическим синдромом и СД2

B

рекомендуется изменение образа жизни.

У больных СД2 с более поздними стадиями заболевания и наличием многочисленных факторов риска и сопутствующей патологией только интенсивный контроль гликемии оказывает лишь умеренное влияние на развитие дистальной симметричной полинейропатии; необходимо достижение целей, индивидуальных для пациента. 


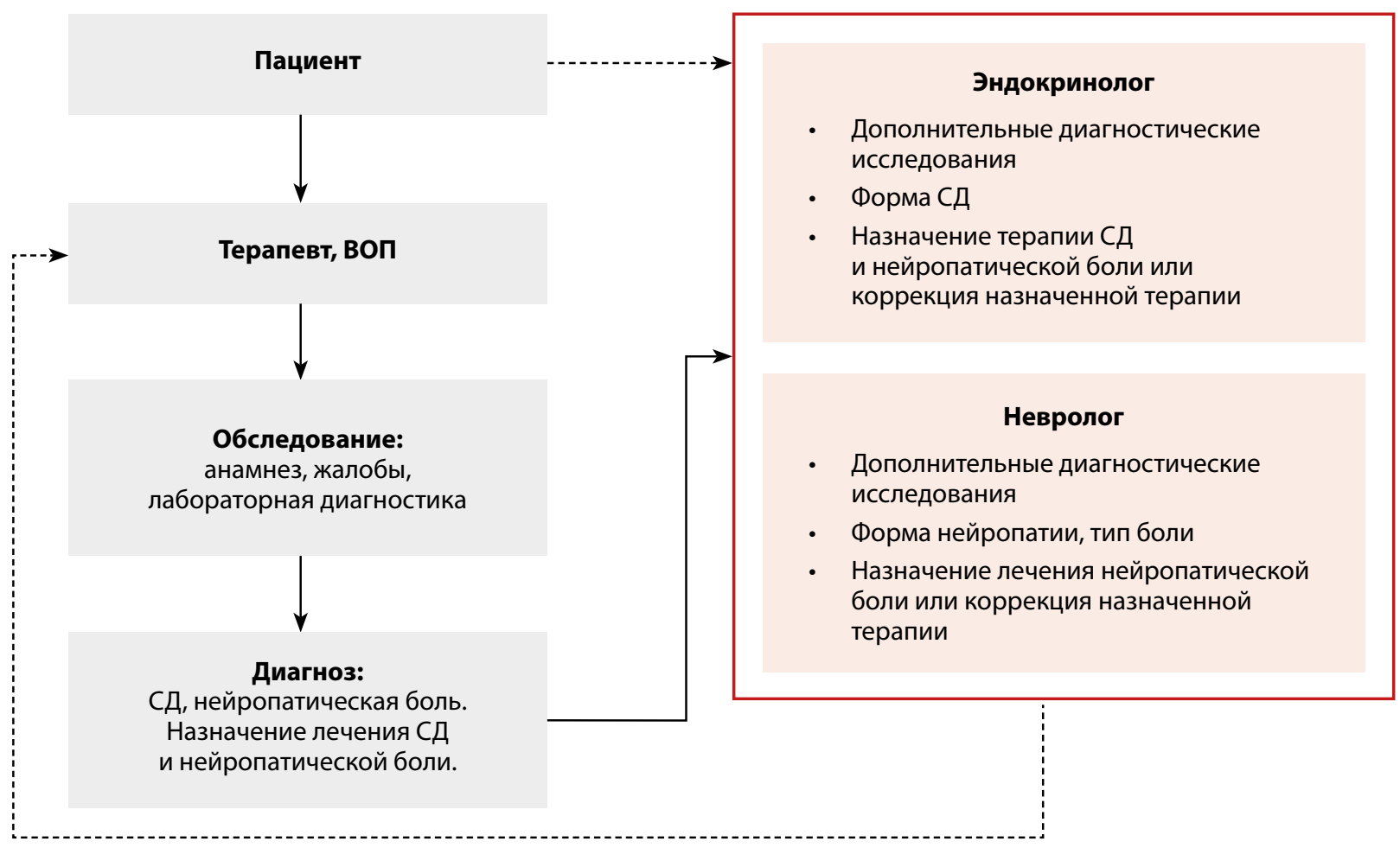

Рис. 3. Схема маршрутизации пациентов с сахарным диабетом и компетенции специалистов

\section{ЛЕЧЕНИЕ БОЛЕВОЙ ДИАБЕТИЧЕСКОЙ ПЕРИФЕРИЧЕСКОЙ НЕЙРОПАТИИ}

\section{Цели лечения БДПН}

Полное купирование болевого синдрома при БДПН не всегда достижимо, поэтому хорошим результатом лечения считается уменьшение его выраженности на 50\% по визуальной аналоговой шкале (ВАШ), а удовлетворительным результатом - уменьшение на 30\%. После уменьшения интенсивности болевого синдрома обычно достигается основная цель лечения - восстановление или улучшение функционирования больного и его качества жизни.

\section{Симптоматическая терапия болевого синдрома}

С учетом сказанного выше, в распоряжении врача имеются лишь различные варианты симптоматической терапии НБ при ДПН, направленные на купирование боли.

Обзор рекомендаций профессиональных ассоциаций по лечению НБ при ДПН и общие принципы терапии

В настоящий момент имеется довольно обширная доказательная база в поддержку фармакотерапии БдПН препаратами разных классов. С этой целью применяются препараты центрального действия (некоторые антидепрессанты, противосудорожные средства и опиоиды). В табл. 7 обобщены рекомендации различных профессиональных ассоциаций и экспертных групп по первой и последующим линиям терапии БДПН. К 1-й линии терапии относятся препараты с наиболее доказанной эффективностью и наилучшим соотношением эффективности и безопасности/ переносимости.

Ко 2-й линии терапии относятся препараты с меньшим объемом доказательных данных при БДПН или с несколько худшей переносимостью.

Наконец, к 3-й линии, или препаратам резерва, относятся препараты, обладающие высокой эффективностью, но имеющие серьезные побочные эффекты.
Все препараты, против которых в таблице указано «1-я» или «2-я» линия, могут использоваться на 1-й линии терапии, а при неэффективности или непереносимости можно перейти на любой другой препарат, также отнесенный к 1-й или 2-й линии.

При назначении каждого препарата следует придерживаться следующих несложных правил.

1. Правило постепенного увеличения (титрования) дозы для лучшей переносимости и выбора минимальной эффективной дозы.

2. Делать вывод о неэффективности того или иного препарата можно только при его приеме в максимальной переносимой дозе в течение времени, строго определенного для каждого препарата (здесь и далее «продолжительность тестовой терапии»).

3. Отмену препаратов в большинстве случаев также желательно производить путем постепенного снижения дозы во избежание развития синдрома отмены и других побочных эффектов. Данное правило неприменимо к тем случаям, когда препарат отменяют из-за аллергических реакций или других тяжелых и серьезных побочных эффектов.

Противосудорожные препараты (антиконвульсанты)

Модуляторы кальциевых каналов (габапентиноиды)

В эту группу входят два препарата с близким строением молекулы - габапентин и прегабалин. Они являются производными гамма-аминомасляной кислоты (ГАМК, англ. аббревиатура - GABA, откуда и образовалось название группы - «габапентиноиды»).

Препараты этой группы связываются не с рецепторами ГАМК, а с а-2- $\delta$-субъединицей потенциалзависимых кальциевых каналов нейронов, что вызывает уменьшение поступления ионов $\mathrm{Ca}^{2+}$ в пресинаптические окончания нейронов, находящихся в состоянии гипервозбуждения. Это ведет к торможению выхода возбуждающих нейромедиаторов в синаптическую 
Таблица 7. Рекомендации профессиональных сообществ по препаратам 1-й, 2-й и 3-й линии для симптоматической терапии нейропатической боли при диабетической периферической нейропатии

\begin{tabular}{|c|c|c|c|c|c|c|c|c|c|}
\hline Препараты & ADA & AAN & EFNS & ASPE & IASP & NeuPSIG & $\begin{array}{c}\text { Toronto } \\
\text { Group }\end{array}$ & CPS & NICE \\
\hline \multicolumn{10}{|l|}{ Антиконвульсанты } \\
\hline Прегабалин* & 1-я & 1-я & $1-9$ & 1-я & 1-я & 1-я & 1-я & 1-я & 1 или 2-я \\
\hline Габапентин & 1-я & 2-я & $1-9$ & 2-я & 1-я & 1-я & 1-я, 2-я & $1-9$ & 1 или 2-я \\
\hline Карбамазепин & - & & - & 2-я & - & - & - & - & - \\
\hline \multicolumn{10}{|l|}{ Антидепрессанты } \\
\hline Трициклические & $1-Я, 2-я^{* *}$ & 2-я (не все) & $1-9$ & $1-9$ & $1-9$ & $1-9$ & 1-я & $1-9$ & 1 или 2-я \\
\hline \multicolumn{10}{|l|}{$\mathrm{CИO3CH}$} \\
\hline Дулоксетин* & $1-9$ & 2-я & $1-9$ & $1-я$ & $1-9$ & $1-9$ & 1-я & $2-9$ & 1 или 2-я \\
\hline \multicolumn{10}{|l|}{ Опиоиды } \\
\hline Трамадол & 3-я & 3-я & 2-я & $2-9$ & 2-я, 3-я & 2-я & 3-я & $2-9$ & 3-я \\
\hline Оксикодон & 3-я & 3-я & 3-я & $1-9$ & 2-я, 3-я & 3-я & $3-9$ & $2-9$ & - \\
\hline Сильные опиоиды & 3-я & $3-9$ & $3-9$ & - & 2-я, 3-я & 3-я & - & $3-9$ & - \\
\hline
\end{tabular}

Примечания: *Зарегистрирован для лечения НБ ПРИ ДПН Управлением по продуктам питания и лекарственным средствам (FDA) США и Европейским агентством по лекарственным средствам (ЕМА).

** К 1-й линии ADA относит ТЦА-вторичные амины, ко 2-й - ТЦА-третичные амины (примеры в тексте).

«-» означает, что препарат в данных клинических рекомендациях не упоминается.

Сокращения: ADA - Американская ассоциация диабета (American Diabetes Association); AAN - Американская неврологическая ассоциация (American Association of Neurology); EFNS - Европейская Федерация неврологических обществ (European Federation of Neurological Societes); ASPE - Американское общество обучателей по вопросам боли (American Society of Pain Educators); IASP - Международная ассоциация по изучению боли (International Association for the Study of Pain); NeuPSIG - Группа по изучению нейропатической боли (Neuropathic Pain Study Interest Group); Toronto Group - Торонтская группа экспертов по изучению нейропатии; CPS - Канадское общество по изучению боли (Сапаdian Раin Society); NICE - Национальный институт клинического качества (National Institute For Clinical Excellence) Великобритании; СИОЗСН - селективные ингибиторы обратного захвата серотонина и норадреналина

щель и замедлению передачи нервного импульса на следующий нейрон. Габапентиноиды действуют только на «перевозбужденные» нейроны в заднем роге спинного мозга и ЦНС и не влияют на нормально функционирующие нейроны. Антидепрессивным действием габапентиноиды не обладают.

Габапентин - первый габапентиноид, внедренный в клиническую практику. Он продемонстрировал эффективность в многочисленных клинических исследованиях лечения боли при ДСПН.

Режим дозирования: начальная доза 300 мг 1 раз в сутки, на 2-й день - 300 мг 2 р/сут, на 3-й день - 300 мг 3 р/сут. В дальнейшем дозу постепенно увеличивают до достижения эффекта, возможно, до 1800-3600 мг/сут. В 2017 г. в РФ была зарегистрирована новая дозировка препарата - 600 мг таблетка с риской.

Минимальная продолжительность тестовой терапии составляет от 3 до 8 нед титрования дозы плюс не менее 2 нед приема в максимальной переносимой дозе.

$N N T^{1}$ габапентина равняется 3-7, то есть как минимум удовлетворительный обезболивающий эффект достигается у 1 из 3-7 пациентов.

Дополнительные положительные эффекты: противотревожный, седативный.

NNT - number needed to treat, число больных, которых необходимо лечить, чтобы получить эффект у одного человека. Здесь и далее под «эффектом» подразумевается уменьшение выраженности боли на 30-50\%.
Наиболее частые побочные эффекты: сонливость, головокружение, атаксия, слабость, периферические отеки. Они могут быть более выраженными у пациентов пожилого и старческого возраста.

Основные противопоказания: повышенная чувствительность к препарату, беременность и лактация, дети до 17 лет.

Меры предосторожности: пациентам с нарушениями функции почек, а также больным, находящимся на гемодиализе, требуется коррекция режима дозирования.

Лекарственные взаимодействия: практически отсутствуют. Антациды уменьшают всасывание габапентина из желудочно-кишечного тракта.

Прегабалин является самым изученным при БДПН препаратом с обезболивающим эффектом, доказанным в большинстве исследований. Его молекула представляет собой модифицированную молекулу габапентина. Сродство молекулы прегабалина к а-2- $\delta$-субъединице $\mathrm{Ca}^{2+}$-канала в 6 раз выше, чем габапентина, а всасывание является линейным и зависит от дозы, что также в положительную сторону отличает прегабалин от габапентина. В связи с этими особенностями фармакокинетики обезболивающий эффект наступает раньше, чем у габапентина, длительный период подбора дозы не требуется. Кроме того, прегабалин эффективнее габапентина: его средняя доза (450 мг/сут) по обезболивающему действию сопоставима с высшей суточной дозой габапентина (3600 мг). Около 50\% больных с БДПН отмечают уменьшение боли на $50 \%$ и более на суточной дозе 
прегабалина 300 мг, а на дозе 600 мг/сут почти у 30\% пациентов отмечается уменьшение болевого синдрома на 70\% и более. Как правило, улучшение появляется уже в первую неделю лечения. Важно, что прегабалин имеет смысл назначать и тем пациентам, которые не ответили или недостаточно ответили на терапию габапентином или трициклическими антидепрессантами (см. далее): у таких больных через 6 мес лечения прегабалином отмечается дополнительное уменьшение болевого синдрома примерно на 25\%.

Режим дозирования: начальная доза: 25-75 мг 1-2 р/сут, с 3-го по 7-й день по 150 мг 2 р/сут, далее при необходимости - по 300 мг 2 р/сут.

Минимальная продолжительность тестовой тераnuи: 2-4 нед в максимальной переносимой дозе.

NNT прегабалина равняется 3-8, то есть минимум удовлетворительный обезболивающий эффект наблюдается у 1 из 3-8 пациентов с НБ при ДПН.

Дополнительные положительные эффекты: стойкое улучшение сна и уменьшение хронической патологической тревоги, часто сопутствующей болевому синдрому.

Наиболее частые побочные эффекты: головокружение (21-46\% больных), сонливость (14-46\% больных), эйфория. Редко встречаются периферические отеки, прибавка массы тела, слабость, головная боль, сухость во рту, атаксия. Обычно головокружение и сонливость возникают в 1-й или 2-й день приема препарата и проходят через 6-17 дней (головокружение) или 26-31 день (сонливость), о чем следует предупредить больного заранее. Из-за плохой переносимости от приема доз 150-300 мг/сут отказываются 2,6\% и 2,1\% больных соответственно, от приема дозы 600 мг/сут 2 до 28\%. Как и при приеме любых психотропных средств, к побочным эффектам более склонны пациенты старческого возраста, которым в связи с этим требуется назначать препарат в меньшей начальной дозе и титровать дозы медленнее.

Основные противопоказания: повышенная чувствительность к препарату, беременность и лактация, дети до 17 лет.

Меры предосторожности: с осторожностью - при отеках (сердечная, почечная недостаточность).

Лекарственные взаимодействия: возможно усиление эффекта седативных препаратов.

Модуляторы натриевых каналов

Карбамазепин, который традиционно назначали для лечения БДПН, не продемонстрировал эффективность по этому показанию, в связи с чем в подавляющем большинстве зарубежных клинических рекомендаций по БДПН карбамазепин не упоминается и в настоящее время не должен использоваться для лечения БДПН.

Окскарбазепин - препарат из той же фармакологической группы, который до последнего времени считался неэффективным при БДПН. Недавно было установлено, что его эффективность зависит от фенотипа НБ: он эффективен при симптомах гипералгезии/аллодинии в сочетании с сохранной чувствительностью, т.е. при клинической картине острой сенсорной (атипичной) БДПН, и неэффективен при БДПН с потерей чувствительности, т.е. хронической сенсорной ДПН. Следовательно, перед назначением этого препарата необходимо определять вариант БДПН, что требует тщательной оценки всех видов чувствительности.
Режим дозирования: начальная доза 2300 мг 2 р/сут, терапевтическая для обезболивания - 1800-2400 мг/сут. Увеличивать дозу рекомендуется после того, как сонливость, возникшая на фоне приема начальной или последующей дозы, уменьшится или пройдет. Этого принципа следует придерживаться на всем протяжении титрования дозы с шагом 300 мг, поэтому в конечном итоге темпы титрования могут быть разными у разных пациентов.

Минимальная продолжительность тестовой терапии: 2-3 нед в максимальной переносимой дозе.

NNT окскарбазепина равняется 3, т.е. хорошее обезболивание достигается у каждого третьего пациента с острой сенсорной НБ при ДПН.

Дополнительные положительные эффекты: улучшение сна.

Наиболее частые побочные эффекты: сонливость, головная боль, головокружение, диплопия, тошнота, рвота, чувство усталости, атаксия, депрессия, тошнота, рвота.

Основные противопоказания: гиперчувствительность к препарату, лактация.

Меры предосторожности: повышенная чувствительность к окскарбазепину и карбамазепину, тяжелая печеночная недостаточность, тяжелая сердечная недостаточность; с крайней осторожностью - при беременности.

Лекарственные взаимодействия: с препаратами, метаболизирующимися с СYР2C19 (фенитоин, фенобарбитал), СҮРЗА4 и СРРЗА5 (дигидропиридиновые антагонисты кальция, пероральные контрацептивы и противоэпилептические препараты).

Антидепрессанты - ингибиторы обратного захвата моноаминов

Препараты, ингибирующие обратный захват моноаминов - серотонина и норадреналина, повышают концентрацию этих нейротрансмиттеров в синаптической щели и оказывают непосредственное влияние на ингибирующую активность нисходящих нейронов, влияя тем самым на центральные механизмы болевой перцепции. Их обезболивающий эффект не зависит от антидепрессивного.

В эту группу относятся селективный ингибитор обратного захвата серотонина и норадреналина (СИО3СН) дулоксетин и трициклические антидепрессанты (ТЦА). В связи с тем, что ТЦА не являются селективными препаратами, они, помимо моноаминов, действуют на центральные гистаминовые рецепторы, а также обладают холинолитическим, альфа-адреноблокирующим и бета-адреностимулирующим и хинидиноподобным эффектами, что определяет их худшую переносимость и большее число противопоказаний, чем у СИОЗСН.

Селективные ингибиторы обратного захвата серотонина и норадреналина

Дулоксетин. В многоцентровых рандомизированных исследованиях была продемонстрирована эффективность доз 60-120 мг/сут в лечении БДПН. Все дозы дулоксетина довольно хорошо переносятся, практически не влияют на гликемию и показатели липидного спектра.

Режим дозирования: начальная доза - 60 мг 1 раз в сутки, эффективные обезболивающие дозы - 60 и 90 мг 1 р/сут и 120 мг/сут в 2 приема. В связи с тем, что в первые 1-2 нед приема дозы 60 мг у некоторых пациентов 
может появляться тревога, которая проявляется нарушением сна, тахикардией или легкой тошнотой («норадреналиновые эффекты»), можно начинать прием с 30 мг/сут с увеличением дозы до 60 мг через неделю. Альтернативой является комбинация 60 мг дулоксетина с небольшими дозами любого противотревожного препарата (валериана 2-3 таблетки в сутки; тофизопам 50 мг 2 р/сут; гидроксизин 12,5-25 мг/сут в один или два приема; тиаприд 50 мг 2 р/сут; феназепам 0,025 мг 1-2 р/сут и т.д.). Через 2-3 недели противотревожный препарат отменяют, а прием дулоксетина продолжают.

Минимальная продолжительность тестовой теpanuи: не менее 4 нед в максимальной переносимой дозе. У большинства пациентов уменьшение болевого синдрома отмечается уже в первые дни приема препарата.

NNT дулоксетина равняется 1,7-7, то есть ослабление болей на 30-50\% и более отмечается примерно у 1 из 2-7 пациентов.

Дополнительные положительные эффекты: доказанное улучшение качества жизни, нарушенного в связи с БДПН; антидепрессивный эффект.

Наиболее частые побочные эффекты: на дозе 60 мг нарушения сна (трудности засыпания или сонливость), легкая тошнота, тахикардия, склонность к запорам; на более высоких дозах - сухость во рту, потливость, усиление или, чаще, - снижение аппетита. Из-за побочных эффектов от приема препарата в дозе 60 мг/сут отказываются 4-10\% больных, в дозе 120 р/сут - 12-19\%. В плацебо-контролируемых исследованиях дулоксетин не повышал уровень $\mathrm{HbA}_{1 с}$ у больных СД; клинически незначимое повышение (разница 0,33\% с контрольной группой) отмечалось лишь в одном долгосрочном исследовании. У пожилых пациентов побочные эффекты могут быть выражены сильнее; их выраженность можно уменьшить назначением меньших начальных доз и более медленным титрованием.

Основные противопоказания: декомпенсированная закрытоугольная глаукома, повышенная чувствительность к препарату, лактация.

Меры предосторожности: печеночная недостаточность, почечная недостаточность со скоростью клубочковой фильтрации (СКФ) менее 30 мл/мин, рефрактерная к терапии артериальная гипертония, эпилепсия, беременность.

Лекарственные взаимодействия: одновременный прием дулоксетина с потенциальными ингибиторами CYP1A2 (фторхинолоны) требует осторожности и снижения доз дулоксетина. Не рекомендуется прием одновременно с ингибиторами МАО и ТЦА.

Неселективные ингибиторы обратного захвата серотонина и норадреналина (трициклические антидепрессанты)

Наиболее известный ТЦА - амитриптилин; кроме него, в эту группу входят имипрамин, дезипрамин, кломипрамин и нортриптилин. В течение многих десятилетий ТЦА используются для лечения хронических болевых синдромов различного генеза, в том числе БДПН. В нескольких рандомизированных слепых плацебо-контролируемых клинических исследованиях было показано значительное уменьшение выраженности НБ. Последний кокрановский обзор поставил под сомнение качество результатов исследований амитриптилина, указав на небольшие размеры выборки в большинстве случаев, и заключил, что в действительности нет ни убедительных доказательств положительного влияния амитриптилина на выраженность болевого синдрома при ДПН, ни доказательств отсутствия эффекта. Однако большой практический опыт применения ТЦА для лечения боли позволяет использовать эти препараты при БДПН.

Амитриптилин, имипрамин и кломипрамин по химическому строению представляют собой третичные амины. ТЦА, которые относятся к вторичным аминам (нортриптилин и дезипрамин), переносятся несколько лучше, чем третичные, однако рандомизированных контролируемых исследований по лечению болевых синдромов этими препаратами проведено меньше и на очень небольших выборках.

Режим дозирования (на примере амитриптилина): начальная доза - 5-10 мг/сут в 2 приема. При хорошей переносимости через 3-4 дня дозу увеличивают до 10-25 мг в 2 приема, дальнейшее увеличение проводится 1 раз в 10-14 дней до достижения терапевтической дозы 50-150 мг/сут в 2-3 приема.

Основные ошибки при назначении амитриптилина: 1) назначение более высоких начальных доз или более быстрое увеличение дозы, в связи с чем больные отказываются от дальнейшего приема из-за побочных эффектов; 2) назначение слишком малых доз амитриптилина - от 2,5 до 25 мг/сут, которые не купируют болевой синдром, и пациенты отказываются от приема препарата из-за мнимой неэффективности.

Минимальная продолжительность тестовой теpanuи: не менее 3 нед в максимальной переносимой дозе.

NNT амитриптилина: 1,3-4, то есть хороший обезболивающий эффект достигается примерно у каждых 3 из 4 пациентов; по другим данным, хотя бы удовлетворительный эффект достигается минимум у каждого четвертого, а хороший эффект - у каждого второго пациента.

Дополнительные положительные эффректы: антидепрессивный и противотревожный эффект, улучшение cHa.

Наиболее частые побочные эфректы: 1) центральные гистаминные (выраженная седация, сонливость, заторможенность, вплоть до спутанности сознания, повышение аппетита и массы тела); 2) холинолитические (спутанность сознания, делирий, когнитивная дисфункция у пожилых при длительном приеме, затруднение мочеиспускания, запоры, сухость во рту, нечеткость зрения, синусовая тахикардия, ишемия миокарда); 3) адренолитические (ортостатическая гипотония, рефлекторная тахикардия, сонливость, головокружение); 4) адренергические (отмечаются только в первые 2 нед применения беспокойство, ощущение «внутренней дрожи», тремор); 5) хинидиноподобные (удлинение интервалов $P R, Q R S$ и QT на ЭКГ, АВ-блокада и другие нарушения проводимости). Побочные эффекты возникают минимум у 25-55\% пациентов и являются причиной прекращения приема амитриптилина у 3-4 из каждых 100 человек.

Основные противопоказания: острый и ранний восстановительный период после инфаркта миокарда, острая алкогольная интоксикация, острая интоксикация 
снотворными, анальгезирующими и психотропными лекарственными средствами, закрытоугольная глаукома, нарушения ритма и проводимости сердца, удлинение интервала QT на ЭКГ; одновременный прием препаратов, удлиняющих интервал QT на ЭКГ; лактация, повышенная чувствительность к амитриптилину, гипертрофия предстательной железы.

Меры предосторожности: крайняя осторожность требуется у больных старческого возраста, при цереброваскулярной болезни, инсульте, хронической ишемии головного мозга любого генеза, ишемической болезни сердца (ИБС), аритмиях, сердечной недостаточности (эти состояния можно считать относительными противопоказаниями). С осторожностью препарат назначают при артериальной гипертонии, склонности к ортостатической гипотонии, в том числе при кардиоваскулярной форме вегетативной ДПН, эпилепсии, СД (нарастание гипергликемии, может потребоваться увеличение дозы сахароснижающих препаратов), хроническом алкоголизме, тиреотоксикозе.

Лекарственные взаимодействия: не применять одновременно с препаратами, оказывающими угнетающее влияние на ЦНС, холинолитиками, симпатомиметиками, ингибиторами моноаминоксидазы (МАО), селективными ингибиторами обратного захвата серотонина (СИОЗС) (возможность токсических реакций), этанолом. При одновременном применении с нейролептиками взаимно угнетается метаболизм, при этом происходит снижение порога судорожной готовности. При одновременном применении с антигипертензивными средствами (за исключением клонидина, гуанетидина и их производных) возможно усиление антигипертензивного действия и риска развития ортостатической гипотензии. При одновременном применении с карбамазепином возможно уменьшение действия амитриптилина вследствие повышения его метаболизма.

Опиоидные и атипичные опиоидные аналгетики

В эту группу входят опиоиды, из которых для лечения БДПН применяют трамадол (смешанный агонист-антагонист мю-опиатных рецепторов, ингибитор обратного захвата серотонина и норадреналина), оксикодон и реже морфин (оба - агонисты каппа-, мю- и дельта-опиатных рецепторов). Будучи наиболее сильными анальгетиками, эти препараты подтвердили свой эффект в тяжелых случаях БДПН и относятся к препаратам глубокого резерва, так как всем им присущ высокий риск развития зависимости, злоупотребления, седативных и других побочных эффектов даже при кратковременном приеме. По этим причинам назначение опиоидов для лечения БДПН возможно только после доказанной неудачи лечения антиконвульсантами или антидепрессантами с соблюдением минимальной тестовой продолжительности терапии.

Трамадол - опиоидный аналгетик центрального действия с меньшим потенциалом развития зависимости и злоупотребления, чем у других опиоидов. Тем не менее его следует использовать лишь в том случае, если все возможности обезболивания с помощью антидепрессантов и противосудорожных средств полностью исчерпаны.

Режим дозирования: начальная доза 50 мг 1-2 р/сут, с постепенным увеличением при необходимости до
100 мг 2-4 р/сут. У пациентов старше 75 лет высшая суточная доза не должна превышать 300 мг в связи с риском нарушения сознания (спутанность).

Минимальная продолжительность тестовой тераnuи: 4 нед приема максимальной переносимой дозы.

NNT трамадола равняется 3-6 (уменьшение боли на 30-50\% и более - у каждого 3-6-го пациента).

Дополнительные положительные эффекты: седативный, противокашлевой.

Наиболее частые побочные эффекты: зависимость, сонливость, слабость, спутанность сознания, сухость во рту, тошнота, рвота, запоры, ортостатическая гипотония, тахикардия, головокружение, головная боль, потливость.

Противопоказания: острая интоксикация алкоголем и препаратами, оказывающими угнетающее влияние на ЦНС, повышенная чувствительность к препарату.

Меры предосторожности: беременность, лактация, печеночная недостаточность, почечная недостаточность, судорожные синдромы.

Лекарственные взаимодействия: с антидепрессантами, действующими на серотонин (группы СИОЗС, СИО3СН, ТЦА), и ингибиторами МАО (опасность развития серотонинового синдрома).

Тапентадол - опиоидный аналгетик центрального действия, являющийся агонистом мю-опиатных рецепторов и ингибитором обратного захвата серотонина. По данным систематического обзора и метаанализа, выполненных группой NeuPSIG, доказательная база по эффективности тапентадола при НБ недостаточно убедительна. Как и другие опиаты, его следует использовать лишь в том случае, если все возможности обезболивания с помощью антидепрессантов и противосудорожных средств полностью исчерпаны.

Режим дозирования: для препарата с немедленным высвобождением начальная доза в первый день 50-100 мг 4-6 р/сут, затем - по 60 мг/сут. Для препарата с замедленным высвобождением начальная доза и поддерживающая доза - 50 мг 2 р/сут.

Минимальная продолжительность тестовой тераnuи: 4 нед приема максимальной переносимой дозы.

NNT тапентадола: неизвестно.

Наиболее частые побочные эффекты: развитие зависимости, рвота, запор, головокружение, нарушения сна, тревога, подавленное настроение, повышенная возбудимость, беспокойство.

Противопоказания: острая интоксикация алкоголем и препаратами, оказывающими угнетающее влияние на ЦНС, повышенная чувствительность к препарату, значительное угнетение дыхания, атония кишечника, тяжелая почечная или печеночная недостаточность.

Меры предосторожности: беременность, лактация, черепно-мозговая травма, судорожный синдром в анамнезе, патология желчных путей, панкреатит.

Лекарственные взаимодействия: может усиливать эффект ингибиторов МАО и антидепрессантов, являющихся селективными ингибиторами обратного захвата норадреналина. Одновременное применение с бензодиазепинами, барбитуратами и опиоидами повышает риск угнетения дыхания. 
Таблица 8. Выбор начальной терапии болевой формы диабетической периферической нейропатии

\section{Основные положения}

Уровень

доказательности

В качестве стартовой симптоматической терапии нейропатической боли при СД могут быть назначены прегабалин или дулоксетин.

A

Габапентин также может быть назначен в качестве эффективной начальной терапии, с учетом сопутствующих заболеваний и потенциальных лекарственных взаимодействий.

Трициклические антидепрессанты также эффективны для лечения нейропатической боли при СД, однако при их назначении необходимо учитывать более высокий риск серьезных побочных эффектов, противопоказаний и лекарственных взаимодействий.

С учетом высокого риска развития зависимости и других осложнений не рекомендуется применение опиоидов, включая трамадол и тапентадол, в качестве 1-й или 2-й линии лечения болевого синдрома при БДПН.

\section{Индивидуальный выбор препарата}

Учитывая достаточно большой перечень препаратов для обезболивания пациентов с БДПН, их выбор следует проводить с учетом:

- доказанной эффективности при БДПН;

- переносимости с учетом профиля пациента;

- возраста пациента;

- сопутствующих заболеваний;

- сопутствующей медикаментозной терапии;

- стоимости и предпочтений пациента.

Рекомендации по выбору препарата для начальной терапии даны в табл. 8.

Критерии выбора препарата первой линии в зависимости от сопутствующих состояний

- Пачиенты старческого возраста: прегабалин, габапентин, реже - дулоксетин.

- Пачиенты с почечной недостаточностью: прегабалин, габапентин, амитриптилин, реже - дулоксетин.

- Пациенты с печеночной недостаточностью: прегабалин, габапентин, реже - амитриптилин.

- Пациенты с сопутствующими сердечно-сосудистыми заболеваниями: прегабалин, габапентин, дулоксетин.

- Пациенты с БДПН и нарушением сна, а также хронической патологической тревогой (ее частота при СД 15-60\%): прегабалин, габапентин.

- Пачиенты с БДПН и депрессией: дулоксетин, амитриптилин.

\section{Депрессия и болевая диабетическая периферическая} нейропатия

Особенно необходима высокая настороженность практических врачей в отношении депрессивных расстройств как возможной причины болевого синдрома [34]. Распространенность депрессии у больных СД достигает 20-30\%, при этом главными жалобами 45-95\% пациентов с СД и депрессией являются именно соматические: постоянная слабость, усталость, отсутствие энергии, упадок сил, непреднамеренное повышение или снижение аппетита и массы тела, бессонница или сонливость, тошнота, запоры, диарея, снижение либидо и эректильная дисфункция, нарушение менструального цикла.

Наиболее типичным соматическим симптомом депрессивных расстройств являются жалобы на боли, не объясняющиесяявнымисоматическимипричинами,-ми- грирующие, меняющие свой характер, наиболее часто боли в конечностях, особенно в ногах, головные боли, боли в пояснице, хронические тазовые боли и т.д. Необходимо быть внимательным к типичным для депрессивного пациента формулировкам болевых жалоб («все болит», «все тело болит», «болят руки и ноги», «каждый день что-нибудь где-нибудь болит»).

Депрессия не только сама способна вызвать болевой синдром, но и усиливает боли при БДПН. Тесная ассоциация депрессии с болями объясняется тем, что и в восприятии боли, и в патогенезе депрессии участвует ряд общих механизмов, главным из которых является дисбаланс нейромедиаторов серотонина и норадреналина в ЦНС.

На практике у больного СД врач может столкнуться с тремя клиническими ситуациями: 1) боли в ногах обусловлены исключительно БДПН; 2) боли в ногах обусловлены только депрессией, а НБ при ДПН отсутствует; 3) боли в ногах обусловлены и БДПН, и депрессией. Конкретная клиническая ситуация будет влиять на выбор медикаментозной обезболивающей терапии НБ при ДПН (см. далее), поэтому выявление депрессии крайне важно. Для скрининга на наличие депрессивных расстройств можно использовать шкалы самоотчета, например, Госпитальную шкалу тревоги и депрессии (HADS) (табл. 9).

Сумма баллов в левой колонке отражает состояние тревоги, в правой колонке - состояние депрессии. Сумма баллов от 8 до 10 означает наличие субклинической тревоги или депрессии, 11 и более баллов - клинически выраженной тревоги или депрессии.

Кроме того, для скрининга депрессивных расстройств врачами-непсихиатрами Всемирная организация здравоохранения предлагает использовать два вопроса:

1. За последние 2 недели ощущали ли Вы подавленность, сниженное настроение или безнадежность?

2. За последние 2 недели ощущали ли Вы снижение или потерю интереса и удовольствия?

Если хотя бы на один из двух скрининговых вопросов дан положительный ответ или набрана диагностическая сумма баллов по шкале HADS, необходимо проводить клиническую диагностику депрессии, в том числе у специалиста. Если при этом у пациента имеется БДПН, то препаратами выбора для купирования боли будут антидепрессанты. 
Таблица 9. Госпитальная шкала тревоги и депрессии.

Прочитайте, пожалуйста, внимательно каждое утверждение и в пустом квадратике поставьте галочку возле ответа, который в наибольшей степени соответствует тому, как Вы чувствовали себя в ПОСЛЕДНЮЮ НЕДЕЛЮ. Первая реакция является наиболее верной.

\section{Т Я испытываю напряженность,} мне не по себе
3 Все время
$\square 2$ Часто
$\square 1$ Время от времени
0 Совсем не испытываю

\section{Т Я испытываю внутреннее напряжение или дрожь}
0 Совсем не испытываю
1 Иногда
$\square 2$ Часто
$\square$ З Очень часто

Т Я испытываю страх, кажется, будто что-то ужасное может вот-вот случиться

3 определенно это так, и страх очень сильный

2 да, это так, но страх не очень сильный

1 иногда, но это меня не беспокоит

0 совсем не испытываю

Т Я испытываю неусидчивость, словно мне постоянно нужно двигаться

3 определенно, это так

$\square 2$ наверное, это так

1 лишь в некоторой степени это так

$\square$ совсем не испытываю

\section{Т Беспокойные мысли крутятся} у меня в голове

3 постоянно

2 большую часть времени

1 время от времени и не так часто

0 только иногда

\section{Т У меня бывает внезапное чувство паники}

3 очень часто

2 довольно часто

1 не так уж и часто

0 совсем не бывает

\section{Т Я легко могу сесть и расслабиться}

0 определенно, это так

1 наверное, это так

2 лишь изредка это так

3 совсем не могу

\section{Д Мне кажется, что я стал все делать очень медленно}
3 Практически все время
$\square 2$ Часто
$\square 1$ Иногда
0 Совсем нет

Д То, что приносило мне большое удовольствие, и сейчас вызывает у меня такое же чувство

$\square$ Определенно, это так

1 Наверное, это так

$\square 2$ Лишь в очень малой степени это так

$\square$ Это совсем не так

\section{Д Я не слежу за своей внешностью}

$\square 3$ определенно, это так

$\square 2$ я не уделяю этому столько времени, сколько нужно

1 может быть, я стал меньше уделять этому внимание

0 я слежу за собой так же, как и раньше

\section{Д Я способен рассмеяться и увидеть В том или ином событии смешное}

$\square 0$ определенно, это так

$\square 1$ наверное, это так

2 лишь в очень малой степени это так

$\square$ совсем не способен

Д Я считаю, что мои дела (занятия, увлечения) могут принести мне чувство удовлетворения

0 точно так же, как и обычно

1 да, но не в той степени, как раньше

$\square 2$ значительно меньше, чем обычно

3 совсем так не считаю

\section{Д Я испытываю бодрость}

3 совсем не испытываю

$\square 2$ очень редко

$\square 1$ иногда

$\square$ практически все время

Д Я могу получить удовольствие от хорошей книги, радио- или телепрограммы
0 часто
1 иногда
2 редко
3 очень редко 


\section{АЛГОРИТМ ПРИНЯТИЯ ТЕРАПЕВТИЧЕСКИХ РЕШЕНИЙ С УЧЕТОМ ЭФФЕКТИВНОСТИ ПРЕПАРАТА}

1. Исходное определение балла боли по шкале ВАШ

3. Уменьшение интенсивности боли до $\leq 3$ баллов по ВАШ

контроль через месяц
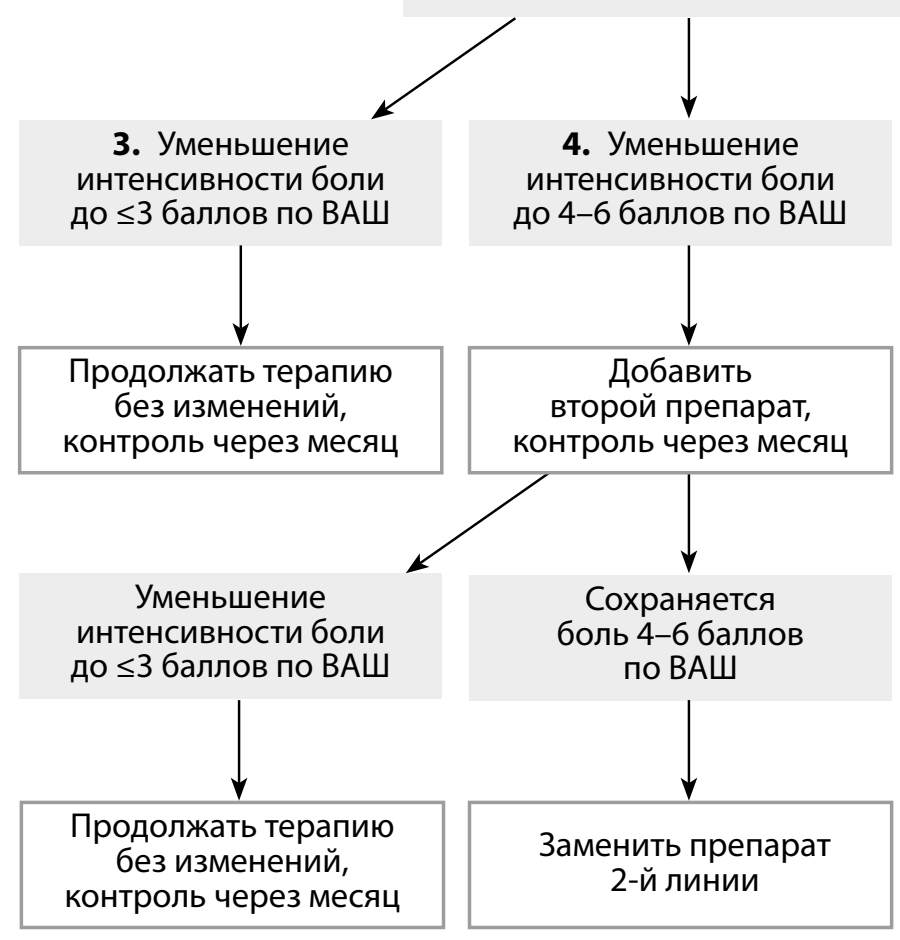

2. Начальная терапия выбранным препаратом

1-й линии в течение минимальной тестовой продолжительности

в максимально переносимой дозе, в конце этого этапа определение интенсивности боли по шкале ВАШ

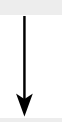

5. Сохраняется боль $\geq 7$ баллов по ВАШ

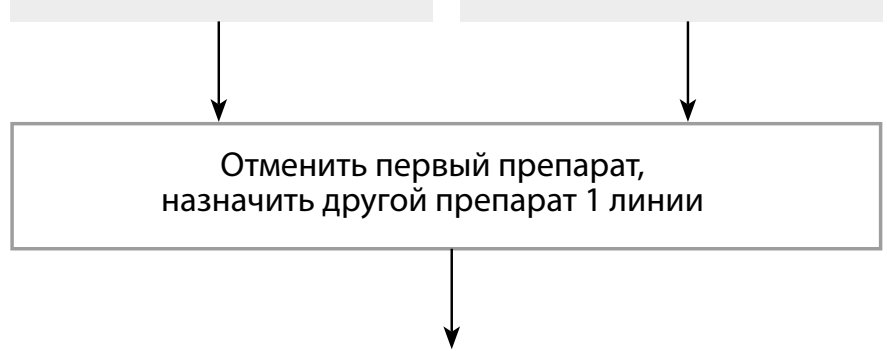

Следовать

пунктам 3 и 4 данного алгоритма

Рис. 4. Алгоритм принятия терапевтических решений с учетом эффективности препарата

\section{ВАРИАНТЫ НАЧАЛА ЛЕЧЕНИЯ И СМЕНЫ ПРЕПАРАТА С УЧЕТОМ ОСНОВНЫХ ФАРМАКОЛОГИЧЕСКИХ КЛАССОВ}

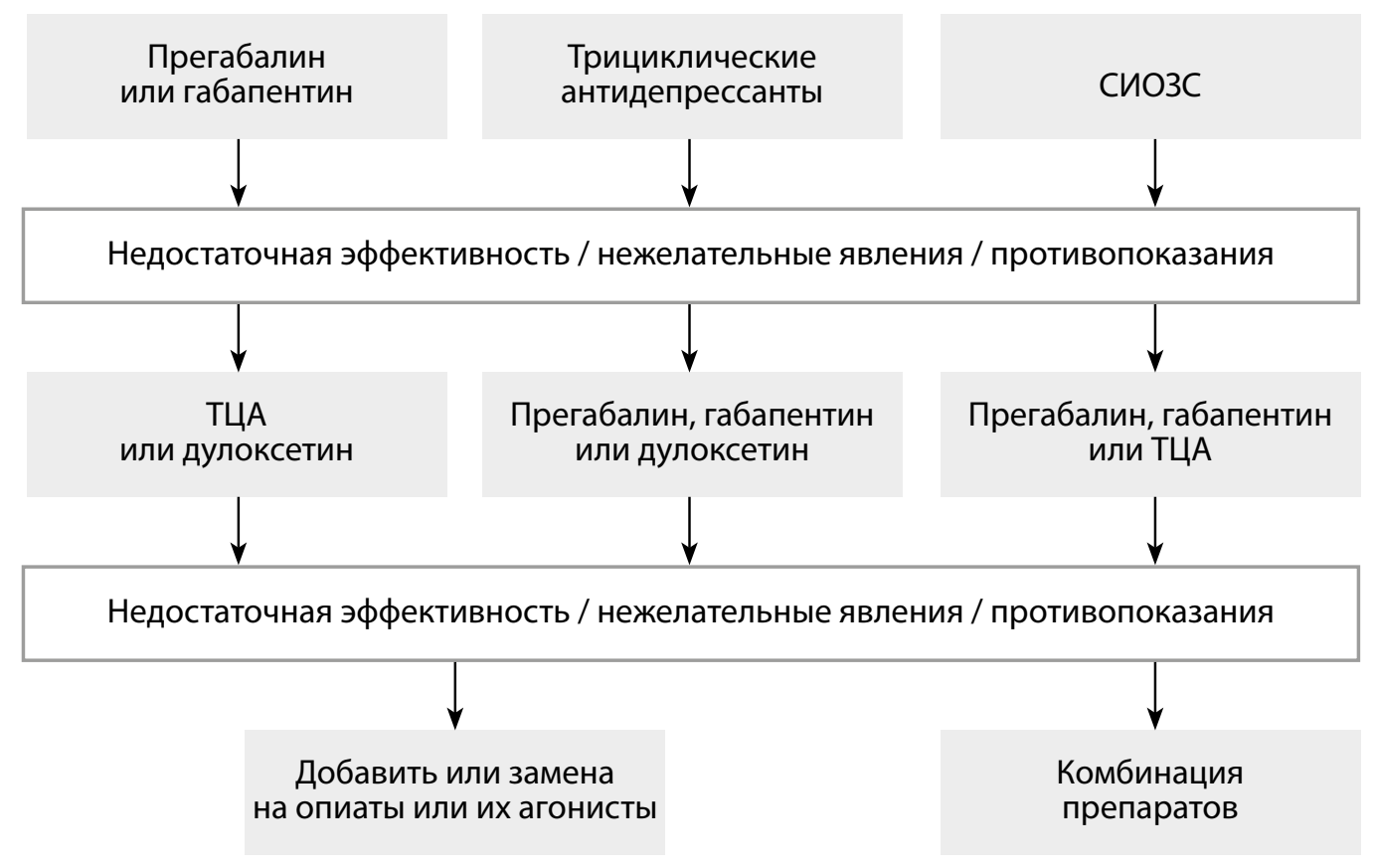

Рис. 5. Варианты начала лечения и смены препарата с учетом основных фармакологических классов. 
Контроль эффективности терапии в динамике и смена препарата

Контроль эффективности лечения должен опираться на субъективную оценку болевого синдрома пациентом. Желательно оценивать выраженность болевого синдрома в динамике с помощью ВАШ и в зависимости от результатов принимать решение о продолжении приема или смене препарата (рис. 4, 5).

- Исходное определение балла боли по ВАШ.

- Начальная терапия выбранным препаратом 1-й линии в течение минимальной тестовой продолжительности в максимально переносимой дозе, в конце этого этапа - определение интенсивности боли по ВАШ.

- Если интенсивность боли уменьшилась до 3 баллов по ВАШ - продолжать терапию, контроль через месяц.

- Если интенсивность боли уменьшилась до 4-5 баллов по ВАШ - добавить второй препарат (см. раздел «комбинированная терапия), контроль через месяц.

- Если интенсивность боли уменьшилась только до 7 баллов по ВАШ или если пациент не переносит назначенный первый препарат, следует отменить его и назначить другой препарат 1-й линии.

- Если комбинированная терапия препаратами 1-й и 2-й линии в течение месяца не уменьшает болевой синдром до менее 7 баллов, следует добавить препарат 3-й линии.

\section{Комбинированная терапия}

Комбинированная терапия, включая комбинации опиоидов, может обеспечить эффективное лечение болевого синдрома при ДПН [34]. В табл. 10 приводятся рекомендации по оптимальному сочетанию препаратов в комбинации и по сочетаниям препаратов, которых нужно избегать.

Большинство указанных в таблице комбинаций основано на двух принципах: 1) сочетание препаратов с разным механизмом действия и 2) избегание лекарственных взаимодействий. По большинству указанных комбинаций качественные рандомизированные клинические исследования не проводились. Единственной комбинацией, подтвердившей свою высокую эффективность и приемлемую безопасность в двойном слепом рандомизированном исследовании с параллельными группами, была комбинация дулоксетина и прегабалина [51].

В этом исследовании пациентов с БДПН, не ответивших на средние дозы обезболивающих препаратов, пе- реводили на высокие дозы дулоксетина (120 мг/сут), или на комбинацию дулоксетина в дозе 60 мг с прегабалином 300 мг/сут, или на высокие дозы прегабалина (600 мг/сут). Значимой разницы в эффективности комбинированной терапии и высокодозной монотерапии прегабалином или дулоксетином по главной конечной точке в целом не получено, однако на комбинации отмечалась существенно более выраженная положительная динамика по многочисленным вторичным конечным точкам, чем на высшей дозе прегабалина. Комбинированная терапия прегабалином и дулоксетином переносилась хорошо.

Хотя некоторым пациентам, не ответившим на все остальные комбинации препаратов, может потребоваться дополнительная терапия «сильными» опиоидами, в этих случаях рекомендуется направить пациента к специалисту по лечению боли для предотвращения сопровождающих лечение рисков.

\section{Не рекомендуемые к применению препараты} для лечения БДПН

В отношении следующих препаратов доказана неэффективность или получены противоречивые результаты по эффективности, не позволяющие рекомендовать их при БДПН [52]:

- из противосудорожных: ламотриджин, лакосамид, вальпроаты, топирамат, зонисамид;

- из антидепрессантов: селективные ингибиторы обратного захвата серотонина (СИОЗС), миансерин, тразодон, ингибиторы МАO;

- из прочих фармакологических групп: клонидин, пентоксифиллин, мексилетин, мемантин, каннабиноиды.

В связи с побочными действиями для лечения БДПН не рекомендуются следующие лекарственные средства:

- нестероидные противовоспалительные средства (НПВС): повышенный риск кровотечений, обострения язвенной болезни, сердечно-сосудистых и цереброваскулярных событий, нефротоксичность при длительном применении;

- ацетаминофен: гепатотоксичность больших доз и при длительном приеме;

- витамин В : нейротоксичность больших доз;

- петидин, тримеперидин (промедол) и пропоксифен (нейротоксичность метаболитов), пентазоцин (нейротоксичность и исчезновение обезболивающего эффекта с течением времени).

Таблица 10. Варианты комбинированной терапии нейропатической боли при диабетической периферической нейропатии

\begin{tabular}{ccc}
\hline Препарат, & Препараты, & Препараты, \\
назначенный первым & $\begin{array}{c}\text { которые целесообразно добавлять } \\
\text { в комбинацию }\end{array}$ & $\begin{array}{c}\text { комбинированного назначения которых } \\
\text { следует избегать }\end{array}$ \\
\hline
\end{tabular}

Прегабалин, габапентин ТЦА, СИОЗСН, трамадол и другие опиоиды Другой препарат из группы габапентиноидов

$\mathrm{CHO} 3 \mathrm{CH}$

ТЦА

Трамадол

Другие опиоиды
Прегабалин, габапентин, опиоиды

Прегабалин, габапентин, опиоиды

Прегабалин, габапентин, опиаты

СИОЗСН, ТЦА, прегабалин, габапентин
Другие СИОЗСН, ТЦА, трамадол

СИОЗСН, трамадол

СИОЗСН, ТЦА 


\section{ПРАВИЛА ВЫПИСКИ ПРЕПАРАТОВ НА РЕЦЕПТУРНЫХ БЛАНКАХ}

С 01.10.2015 г., согласно Приказу Минздрава России от 30.06.2015 № 386н «О внесении изменений в приложения к приказу Министерства здравоохранения Российской Федерации от 20 декабря 2012 г. № 1175н «Об утверждении порядка назначения и выписывания лекарственных препаратов, а также форм рецептурных бланков на лекарственные препараты, порядка оформления указанных бланков, их учета и хранения»», лекарственный препарат прегабалин был включен в перечень предметно-количественно учета (ПКУ), раздел IV «Иные лекарственные средства, подлежащие предметно-количественному учету: прегабалин, тропикамид, циклопентолат, тапентадол) с требованиями выписывания препаратов на форме рецептурного бланка 148-1/y-88 с соответствующими реквизитами, согласно Приказу № 1175н» [53].

\section{Важные правила заполнения рецептов 148-1/y-88}

- Отпуск всего выписанного на рецепте количества препарата осуществляется единовременно, без возможности последующего возврата рецепта пациенту.

- На 1 рецепт - 1 МНН только одной дозировки. При необходимости выписывания на курс различных дозировок препарата необходим отдельный рецепт на каждую дозировку.

- Учет рецептов в аптеке.

- В медицинскую карту пациента вносятся номер и серия рецепта.

- Исправления в рецепте, выписанном на рецептурном бланке, не допускаются.

- Рецепт заполняется разборчиво, четко, чернилами или шариковой ручкой.

- Рецепт, выписанный с нарушением установленных настоящим Порядком требований, считается недействительным.

- Допускается оформление всех реквизитов (за исключением реквизита «Подпись лечащего врача») с использованием печатающих устройств.

- Сведения о назначенном и выписанном лекарственном препарате (наименование лекарственного средства, разовая доза, способ и кратность приема или введения, длительность курса, обоснование назначенного лекарственного средства) указываются в медицинской карте пациента.

- Указания в графе «Rр» рецептурных бланков

- На латинском языке наименование лекарственного препарата (международное непатентованное, при его отсутствии - группировочное, при его отсутствии торговое), его дозировка.
- Разрешаются только принятые правилами сокращения обозначений; твердые и сыпучие фармацевтические субстанции выписываются в граммах $(0,001 ; 0,5$; 1,0), жидкие - в миллилитрах, граммах и каплях.

- На русском или русском и национальном языках способ применения лекарственного препарата.

- Запрещается ограничиваться общими указаниями, например, «внутреннее», «известно».

- Способ применения лекарственного препарата обозначается с указанием дозы, частоты, времени приема относительно сна (утром, на ночь) и его длительности, а для лекарственных препаратов, взаимодействующих с пищей, - времени их употребления относительно приема пищи (до еды, во время еды, после еды).

\section{Печати на бланке рецепта}

В левом верхнем углу проставляется штамп медицинской организации с указанием ее наименования, адреса и телефона (это очень важный реквизит, т.к. у фармацевта должна быть обеспечена связь с ЛПУ в случае неправильно выписанного рецепта).

Рецепт, выписанный на рецептурном бланке, подписывается медицинским работником и заверяется его личной печатью (должность медицинского работника вписывать не нужно).

Дополнительно рецепт заверяется печатью медицинской организации «Для рецептов».

При выписке лекарственного препарата по решению врачебной комиссии на обороте рецептурного бланка дополнительно ставится специальная отметка («Штамп»).

Назначение и выписывание препаратов по решению врачебной комиссии производится, в частности, при первичном назначении пациенту наркотических и психотропных лекарственных препаратов списков II и III Перечня (в случае принятия руководителем медицинской организации решения о необходимости согласования назначения таких лекарственных препаратов с врачебной комиссией).

Для выписывания прегабалина, согласно законодательству, не требуется дополнительных согласований с администрацией ЛПу, не требуется решение о выписке врачебной комиссии. На рецепте ставится только подпись медицинского работника, дополнительных подписей администрации ЛПУ не требуется. Для выписывания прегабалина не установлено предельно допустимой нормы на один рецепт и на курс. Врач имеет право выписать любое количество капсул одной дозировки на курс на одном рецепте. Если имеется необходимость выписать сразу две дозировки препарата прегабалин, то на каждую дозировку выписывается отдельный рецепт формы 148-1/y-88.

\section{СПИСОК ЛИТЕРАТУРЫ | REFERENCES}

1. Дедов И.И., Шестакова М.В., Викулова О.К. Эпидемиология сахарного диабета в Российской Федерации: клиникостатистический анализ по данным Федерального регистра сахарного диабета // Сахарный диабет. - 2017. - Т. 20. — №1. - C. 13-41. [Dedov II, Shestakova MV, Vikulova OK. Epidemiology of diabetes mellitus in Russian Federation: clinical and statistical report according to the federal diabetes registry. Diabetes mellitus. 2017;20(1):13-41. (In Russ.)] doi: https://doi.org/10.14341/DM8664
Дедов И.И., Шестакова М.В., Майоров А.Ю., и др. Алгоритмы специализированной медицинской помощи больным сахарным диабетом. / Под ред. И.И. Дедова, М.В. Шестаковой, А.Ю. Майорова. - 9-й выпуск // Сахарный дuaбem. - 2019. - T. 22. — №1S. [Dedov II, Shestakova MV, Mayorov AY, et al. Standards of specialized diabetes care. 9th edition. Diabetes mellitus. 2019;22(1S). (In Russ.)] doi: https://doi.org/10.14341/DM221S1 
3. Болевые синдромы в неврологической практике. / Под ред. Вейна A.M. - M.; 2001. [Veyn AM, editor. Bolevye sindromy v nevrologicheskoy praktike. Moscow; 2001. (In Russ.)]

4. Hansson P, Fields H, Hill R, Marchettini P, editors. Neuropathic Pain: Pathophysiology and Treatment, Progress in Pain Research and Management. Seattle: IASP Press; 2001.

5. Яхно Н.Н., Давыдов О.С. Неврологическая боль. Современное состояние проблемы. В кн.: Болезни мозга - медицинские и сочиальные аспекты / Под ред. Е.И. Гусева, А.Б Гехт. - М.: БукиВеди, 2016. - C.605-627. [Yakhno NN, Davidov OS. Neuropathic pain. The current state of the problem. In: Gusev El, Gecht AB, editors. Brain Diseases - Medical and Social Aspects. Moscow: Buki-Vedi; 2011. p.605-627. (In Russ.)]

6. Боль. Практическое руководство для врачей. / Под ред. Яхно Н.H. - М.: Издательство РАMН AНО, 2011. [Yakhno NN, editor. Pain. Practical guide for doctors. Moscow: RAMN ANO; 2011. (In Russ.)]

7. van Hecke O, Austin SK, Khan RA et al. Neuropathic pain in the general population: a systematic review of epidemiological studies. Pain. 2014;155(4):654-662. doi: https://doi.org/10.1016/j.pain.2013.11.013

8. DiBonaventura MD, Sadosky A, Concialdi K. The prevalence of probable neuropathic pain in the US: results from a multimodal general-population health survey. J Pain Res. 2017;10:2525-2538. doi: https://doi.org/10.2147/JPR.S127014

9. Яхно Н.Н., Кукушкин М.Л., Давыдов О.С. Результаты российского эпидемиологического исследования распространенности невропатической боли, ее причин и характеристик в популяции амбулаторных больных, обратившихся к врачу-неврологу // Боль. - 2008. — №3. - C. 24-32. [Yakhno NN, Kukushkin ML, Davidov OS. Rezul'taty rossijskogo jepidemiologicheskogo issledovanija rasprostranennosti nevropaticheskoj boli, ee prichin i harakteristik v populjacii ambulatornyh bol'nyh, obrativshihsja k vrachu-nevrologu. Bol.' 2008;(3):24-32. (In Russ.)]

10. Яхно Н.Н., Кукушкин М.Л., Чурюканов М.В., Сыровегин А.В Результаты открытого мультицентрового исследования «МЕРИДИАН» по оценке распространенности болевых синдромов в амбулаторной практике и терапевтических предпочтений врачей // Российский журнал боли. - 2012. — №3-4. — C. 10-14. [Yahno NN, Kukushkin ML, Churyukanov MV, Syrovegin AV. The results of open multicentral study "Meridian" for assessment of pain syndromes prevalence in ambulatory and therapeutic preferences of physicians. Russian journal of pain. 2012;(3-4):10-14. (In Russ.)]

11. Pop-Busui R, Boulton AJ, Feldman EL, et al. Diabetic Neuropathy: A Position Statement by the American Diabetes Association. Diabetes Care. 2017;40(1):136-154. doi: https://doi.org/10.2337/dc16-2042

12. Albers JW, Pop-Busui R. Diabetic neuropathy: mechanisms, emerging treatments, and subtypes. Curr Neurol Neurosci Rep. 2014;14(8):473. doi: https://doi.org/10.1007/s11910-014-0473-5

13. Dyck PJ, Albers JW, Andersen H, et al. Diabetic polyneuropathies: update on research definition, diagnostic criteria and estimation of severity. Diabetes Metab Res Rev. 2011;27(7):620-628. doi: https://doi.org/10.1002/dmrr.1226

14. Biessels GJ, Bril V, Calcutt NA, et al. Phenotyping animal models of diabetic neuropathy: a consensus statement of the diabetic neuropathy study group of the EASD (Neurodiab). J Peripher Nerv Syst. 2014;19(2):77-87. doi: https://doi.org/10.1111/jns5.12072

15. O'Brien PD, Hinder LM, Sakowski SA, Feldman EL. ER stress in diabetic peripheral neuropathy: A new therapeutic target. Antioxid Redox Signal. 2014;21(4):621-633. doi: https://doi.org/10.1089/ars.2013.5807

16. Vincent AM, Callaghan BC, Smith AL, Feldman EL. Diabetic neuropathy: cellular mechanisms as therapeutic targets. Nat Rev Neurol. 2011;7(10):573-583. doi: https://doi.org/10.1038/nrneurol.2011.137

17. Malik RA, Veves A, Tesfaye $S$, et al. Small fibre neuropathy: role in the diagnosis of diabetic sensorimotor polyneuropathy. Diabetes Metab Res Rev. 2011;27(7):678-684. doi: https://doi.org/10.1002/dmrr.1222

18. Baron R, Tolle TR, Gockel U, et al. A cross-sectional cohort survey in 2100 patients with painful diabetic neuropathy and postherpetic neuralgia: Differences in demographic data and sensory symptoms. Pain 2009;146(1-2):34-40. doi: https://doi.org/10.1016/j.pain.2009.06.001

19. Freeman R, Baron R, Bouhassira D, et al. Sensory profiles of patients with neuropathic pain based on the neuropathic pain symptoms and signs. Pain. 2014;155(2):367-376. doi: https://doi.org/10.1016/j.pain.2013.10.023

20. Daousi C, MacFarlane IA, Woodward A, et al. Chronic painful peripheral neuropathy in an urban community: a controlled comparison of people with and without diabetes. Diabet Med. 2004;21(9):976-982. doi: https://doi.org/10.1111/j.1464-5491.2004.01271.x
21. Davies M, Brophy S, Williams R, Taylor A. The prevalence, severity, and impact of painful diabetic peripheral neuropathy in type 2 diabetes. Diabetes Care. 2006;29(7):1518-1522. doi: https://doi.org/10.2337/dc05-2228

22. Ziegler D, Rathmann W, Dickhaus T, et al. Neuropathic pain in diabetes, prediabetes and normal glucose tolerance: the MONICA/ KORA Augsburg Surveys S2 and S3. Pain Med. 2009;10(2):393-400. doi: https://doi.org/10.1111/j.1526-4637.2008.00555.x

23. Vileikyte L, Leventhal H, Gonzalez JS, et al. Diabetic Peripheral Neuropathy and Depressive Symptoms: The association revisited. Diabetes Care. 2005;28(10):2378-2383. doi: https://doi.org/10.2337/diacare.28.10.2378

24. Vileikyte L, Rubin RR, Leventhal H. Psychological aspects of diabetic neuropathic foot complications: an overview. Diabetes Metab Res Rev. 2004;20 Suppl 1:S13-18. doi: https://doi.org/10.1002/dmrr.437

25. VinikE, Silva MP, Vinik Al. Measuring the relationship of quality of life and health status, including tumor burden, symptoms, and biochemical measures in patients with neuroendocrine tumors. Endocrinol Metab Clin North Am. 2011;40(1):97-109, viii. doi: https://doi.org/10.1016/j.ecl.2010.12.008

26. Boulton AJM, Malik RA, Arezzo JC, Sosenko JM. Diabetic Somatic Neuropathies. Diabetes Care. 2004;27(6):1458-1486. doi: https://doi.org/10.2337/diacare.27.6.1458

27. Perkins BA, Olaleye D, Zinman B, Bril V. Simple Screening Tests for Peripheral Neuropathy in the Diabetes Clinic. Diabetes Care. 2001;24(2):250-256. doi: https://doi.org/10.2337/diacare.24.2.250

28. Tan LS. The clinical use of the $10 \mathrm{~g}$ monofilament and its limitations: a review. Diabetes Res Clin Pract. 2010;90(1):1-7. doi: https://doi.org/10.1016/j.diabres.2010.06.021

29. Boulton AJ, Armstrong DG, Albert SF, et al. Comprehensive foot examination and risk assessment: a report of the task force of the foot care interest group of the American Diabetes Association, with endorsement by the American Association of Clinical Endocrinologists. Diabetes Care. 2008;31(8):1679-1685. doi: https://doi.org/10.2337/dc08-9021

30. Archer AG, Watkins PJ, Thomas PK, et al. The natural history of acute painful neuropathy in diabetes mellitus. J Neurol Neurosurg Psychiatry. 1983;46(6):491-499. doi: https://doi.org/10.1136/jnnp.46.6.491

31. Boulton AJM, Vinik Al, Arezzo JC, et al. Diabetic Neuropathies: A statement by the American Diabetes Association. Diabetes Care. 2005;28(4):956-962. doi: https://doi.org/10.2337/diacare.28.4.956

32. Tesfaye S, Boulton AJ, Dyck PJ, et al. Diabetic neuropathies: update on definitions, diagnostic criteria, estimation of severity, and treatments. Diabetes Care. 2010;33(10):2285-2293. doi: https://doi.org/10.2337/dc10-1303

33. Gibbons $\mathrm{CH}$, Freeman R. Treatment-induced neuropathy of diabetes: an acute, iatrogenic complication of diabetes. Brain. 2015;138(Pt 1):4352. doi: https://doi.org/10.1093/brain/awu307

34. Старостина Е.Г. Диабетическая нейропатия: некоторые вопросы дифференциальной диагностики и системной терапии болевого синдрома // РМЖ. - 2017. - T. 25. — №22. — C. 3-14. [Starostina EG. Diabetic neuropathy: some issues in differential diagnosis and systemic treatment of the pain syndrome. RMZh. 2017;25(22):2-14. (In Russ.)]

35. Diabetes Control and Complications Research Group. The effect of intensive treatment of diabetes on the development and progression of long-term complications in insulindependent diabetes mellitus. N Engl J Med. 1993;329(14):977-986. doi: https://doi.org/10.1056/NEJM199309303291401

36. Diabetes Control and Complications Research Group. Effect of intensive diabetes treatment on nerve conduction in the Diabetes Control and Complications Trial. Ann Neurol. 1995;38(6):869-880. doi: https://doi.org/10.1002/ana.410380607

37. Linn T, Ortac K, Laube H, Federlin K. Intensive therapy in adult insulindependent diabetes mellitus is associated with improved insulin sensitivity and reserve: A randomized, controlled, prospective study over 5 years in newly diagnosed patients. Metabolism. 1996;45(12):1508-1513. doi: https://doi.org/10.1016/s0026-0495(96)90180-8

38. Callaghan $\mathrm{BC}$, Cheng HT, Stables $\mathrm{CL}$, et al. Diabetic neuropathy: clinical manifestations and current treatments. Lancet Neurol. 2012;11(6):521534. doi: https://doi.org/10.1016/s1474-4422(12)70065-0

39. Ismail-Beigi F, Craven T, Banerji MA, et al. Effect of intensive treatment of hyperglycaemia on microvascular outcomes in type 2 diabetes: an analysis of the ACCORD randomised trial. Lancet. 2010;376(9739):419430. doi: https://doi.org/10.1016/s0140-6736(10)60576-4

40. Ohkubo Y, Kishikawa H, Araki E, et al. Intensive insulin therapy prevents the progression of diabetic microvascular complications in Japanese patients with non-insulin-dependent diabetes mellitus: a randomized prospective 6-year study. Diabetes Res Clin Pract. 1995;28(2):103-117. doi: https://doi.org/10.1016/0168-8227(95)01064-k 
41. Ismail-Beigi F, Craven T, Banerii MA, et al. Effect of intensive treatment of hyperglycaemia on microvascular outcomes in type 2 diabetes: an analysis of the ACCORD randomised trial. Lancet. 2010;376(9739):419430. doi: https://doi.org/10.1016/S0140-6736(10)60576-4

42. Charles M, Ejskjaer N, Witte DR, et al. Prevalence of neuropathy and peripheral arterial disease and the impact of treatment in people with screen-detected type 2 diabetes: the ADDITION-Denmark study. Diabetes Care. 2011;34(10):2244-2249. doi: https://doi.org/10.2337/dc11-0903

43. Charles $\mathrm{M}$, Fleischer J, Witte DR, et al. Impact of early detection and treatment of diabetes on the 6-year prevalence of cardiac autonomic neuropathy in people with screen-detected diabetes: ADDITION-Denmark, a cluster-randomised study. Diabetologia. 2012;56(1):101-108. doi: https://doi.org/10.1007/s00125-012-2744-5

44. Ang L, Jaiswal M, Martin C, Pop-Busui R. Glucose control and diabetic neuropathy: lessons from recent large clinical trials. Curr Diab Rep. 2014;14(9):528. doi: https://doi.org/10.1007/s11892-014-0528-7

45. Pop-Busui R, Lu J, Brooks MM, et al. Impact of glycemic control strategies on the progression of diabetic peripheral neuropathy in the Bypass Angioplasty Revascularization Investigation 2 Diabetes (BARI 2D) Cohort. Diabetes Care. 2013;36(10):3208-3215. doi: https://doi.org/10.2337/dc13-0012

46. Gaede $P$, Vedel $P$, Larsen N, et al. Multifactorial intervention and cardiovascular disease in patients with type 2 diabetes. N Engl J Med. 2003;348(5):383-393. doi: https://doi.org/10.1056/NEJMoa021778

47. Balducci $S$, lacobellis $G$, Parisi L, et al. Exercise training can modify the natural history of diabetic peripheral neuropathy. J Diabetes Complications. 2006;20(4):216-223. doi: https://doi.org/10.1016/j.jdiacomp.2005.07.005

48. Singleton JR, Marcus RL, Jackson JE, et al. Exercise increases cutaneous nerve density in diabetic patients without neuropathy. Ann Clin Trans/ Neurol. 2014;1(10):844-849. doi: https://doi.org/10.1002/acn3.125
49. Carnethon MR, Prineas RJ, Temprosa M, et al. The Association Among Autonomic Nervous System Function, Incident Diabetes, and Intervention Arm in the Diabetes Prevention Program. Diabetes Care. 2006;29(4):914919. doi: https://doi.org/10.2337/diacare.29.04.06.dc05-1729

50. Smith AG, Russell J, Feldman EL, et al. Lifestyle intervention for pre-diabetic neuropathy. Diabetes Care. 2006;29(6):1294-1299. doi: https://doi.org/10.2337/dc06-0224

51. Tesfaye $\mathrm{S}$, Wilhelm S, Lledo A, et al. Duloxetine and pregabalin: high-dose monotherapy or their combination? The «COMBO-DN study»--a multinational, randomized, double-blind, parallel-group study in patients with diabetic peripheral neuropathic pain. Pain. 2013;154(12):2616-2625. doi: https://doi.org/10.1016/j.pain.2013.05.043

52. Finnerup NB, Attal N, Haroutounian S, et al. Pharmacotherapy for neuropathic pain in adults: a systematic review and meta-analysis. Lancet Neurol. 2015;14(2):162-173. doi: https://doi.org/10.1016/S1474-4422(14)70251-0

53. Приказ МЗ РФ от 30.06.2015 № 386н «О внесении изменений в приложения к приказу Министерства здравоохранения Российской Федерации от 20 декабря 2012 г. №1175н «Об утверждении порядка назначения и выписывания лекарственных препаратов, а также форм рецептурных бланков на лекарственные препараты, порядка оформления указанных бланков, их учета и хранения»». [Order of the Ministry of Health of the Russian Federation of 30 Jun 2015 № 386 $\mathrm{H}$ «O vnesenii izmeneniy v prilozheniya k prikazu Ministerstva zdravookhraneniya Rossiyskoy Federatsii ot 20 dekabrya 2012 g. №1175n «Ob utverzhdenii poryadka naznacheniya i vypisyvaniya lekarstvennykh preparatov, a takzhe form retsepturnykh blankov na lekarstvennye preparaty, poryadka oformleniya ukazannykh blankov, ikh ucheta i khraneniya»»». (In Russ.)]

\section{ИНФОРМАЦИЯ ОБ АВТОРАХ [AUTHORS INFO]}

*Галстян Гагик Радикович, д.м.н., профессор [Gagik R. Galstyan, MD, PhD, Professor]; адрес: Россия, 117036 Москва, ул. Дм. Ульянова, д. 11 [address: 11 Dm. Ulyanova street, 117036 Moscow, Russian Federation]; ORCID: https://orcid.org/0000-0001-6581-4521; eLibrary SPIN: 9815-7509; e-mail: galstyangagik964@gmail.com

Старостина Елена Георгиевна, д.М.H., професcop [Elena G. Starostina, MD, PhD, Professor]; ORCID: https://orcid.org/0000-0002-3328-2812; eLibrary SPIN: 6977-0793; e-mail: elena.starostina@rambler.ru

Яхно Николай Николаевич, д.м.н., профессор, академик PAH [Nikolay N. Yakhno, MD, PhD, Professor]; ORCID: https://orcid.org/0000-0002-8255-5645; eLibrary SPIN: 6438-3370; e-mail: yahno@mma.ru Гурьева Ирина Владимировна, д.м.н., профессор [Irina V. Gurieva, MD, PhD, Professor]; eLibrary SPIN: 9376-7686; e-mail: igurieva@mail.ru

Чурюканов Максим Валерьевич, к.М.н., доцент [Maxim V. Churyukanov, MD, PhD, associate professor]; ORCID: https://orcid.org/0000-0001-6542-1963; eLibrary SPIN: 7968-2812; e-mail: mchurukanov@gmail.com

Строков Игорь Алексеевич, доцент, к.м.н. [lgor A. Strokov, MD, PhD, associate professor];

ORCID: https://orcid.org/0000-0001-6950-7166; eLibrary SPIN: 5262-8780; e-mail: strigoral@mail.ru

Токмакова Алла Юрьевна, д.м.н. [Alla Y. Tokmakova, MD, PhD]; ORCID: https://orcid.org/0000-0003-2474-9924;

eLibrary SPIN: 7479-7043; e-mail: alla-tokmakova@yandex.ru

Кукушкин Михаил Львович, д.м.H., профессор [Mikhail L. Kukushkin, MD, PhD, Professor] ORCID: https://orcid.org/0000-0002-9406-5846; eLibrary SPIN: 2810-1998; e-mail: mkuk57@gmail.com

Мартынов Анатолий Иванович, д.М.н., профессор, академик PAH [Anatoly I. Martynov, MD, PhD, Professor]; ORCID: https://orcid.org/0000-0002-9176-2128; eLibrary SPIN: 5271-3173; e-mail: anatmartynov@mail.ru Шестакова Марина Владимировна, д.м.н., профессор, академик PAH [Marina V. Shestakova, MD, PhD, Professor]; ORCID: https://orcid.org/0000-0002-5057-127X; eLibrary SPIN: 7584-7015; e-mail: nephro@endocrincentr.ru

\section{ЦИТИРОВАТЬ:}

Галстян Г.Р, Старостина Е.Г., Яхно Н.Н., Гурьева И.В., Чурюканов М.В., Строков И.А., Токмакова А.Ю., Кукушкин М.Л., Мартынов А.И., Шестакова М.В. Диагностика и рациональная терапия болевой формы диабетической периферической нейропатии: междисциплинарный консенсус экспертов // Сахарный диабет. - 2019. — Т. 22. — №4. — С. $305-327$. doi: 10.14341/DM9625

\section{TO CITE THIS ARTICLE:}

Galstyan GR, Starostina EG, Yakhno NN, Gurieva IV, Churukanov MV, Strokov IA, Tokmakova AY, Kukushkin ML, Martynov AI, Shestakova MV. Diagnosis and rational treatment of painful diabetic peripheral neuropathy: an interdisciplinary expert consensus. Diabetes Mellitus. 2019;22(4):305-327. doi: 10.14341/DM9625 